\title{
Performance Evaluation and Enhancement of M-Ary DPPM Modulation for WDM-PON/FSO Systems Impaired by Atmospheric Turbulence, Interchannel Crosstalk, and ASE Noise
}

\section{Ebrahim E. Elsayed ( $\sim$ engebrahem16@gmail.com )}

Electronics and Communications Engineering Department, Faculty of Engineering-Mansoura University, Mansoura 35516, El-Dakahilia, Egypt. https://orcid.org/0000-0002-7208-2194

\section{Bedir B. Yousif}

Electrical Engineering Department, Branch of Electronics and Communications Engineering-Faculty of Engineering, Kafrelsheikh University, Kafrelsheikh 33511, Kafrelsheikh, Egypt.

\section{Research Article}

Keywords: Amplified spontaneous emission (ASE) noisel, Interchannel crosstalk, Wavelength division multiplexing (WDM) systems/PON; M-ary digital pulse-position modulation (M-ary DPPM), Free-space optical (FSO) communications, Modified Chernoff bound (MCB)

Posted Date: October 15th, 2020

DOI: https://doi.org/10.21203/rs.3.rs-92701/v1

License: (c) (1) This work is licensed under a Creative Commons Attribution 4.0 International License. Read Full License

Version of Record: A version of this preprint was published at Optical and Quantum Electronics on October 15th, 2020. See the published version at https://doi.org/10.1007/s11082-021-03485-8. 


\title{
Performance Evaluation and Enhancement of M-Ary DPPM Modulation for WDM-PON/FSO Systems Impaired by Atmospheric Turbulence, Interchannel Crosstalk, and ASE Noise
}

\author{
Ebrahim E. Elsayed $^{1}{ }^{*}$, Bedir B. Yousif ${ }^{2}$ \\ ${ }^{I}$ Electronics and Communications Engineering Department, Faculty of Engineering-Mansoura \\ University, Mansoura 35516, El-Dakahilia, Egypt. \\ ${ }^{2}$ Electrical Engineering Department, Branch of Electronics and Communications Engineering-Faculty \\ of Engineering, Kafrelsheikh University, Kafrelsheikh 33511, Kafrelsheikh, Egypt.
}

(*Corresponding author's email: engebrahem16@gmail.com)

Running title

M-ary DPPM for WDM-FSO Systems

\begin{abstract}
This paper analyzes and enhances the performance of moment generating function techniques, notably the Chernoff bound (CB) and modified Chernoff bound (MCB), is used to improve the bit-errorrate (BER) performance of an optically pre-amplified for the wavelength division multiplexing (WDM) based on the passive optical network (PON) free-space optical (FSO) communications in the presence of both atmospheric turbulence (AT), amplified spontaneous emission (ASE) noise, and interchannel crosstalk. In the absence of AT and ASE at a data rate of $2.5 \mathrm{Gbps}$ on the $1550 \mathrm{~nm}$ wavelength, digital pulse-position modulation (DPPM) systems with coding level (M) of 2 provide about 2.9 dB improvement in average power over at a BER of $10^{-9}$ (depending on the turbulence level) compared with an equivalent on-off keying (OOK) non-return-to-zero (NRZ) in the WDM-PON/FSO system while maintaining minimum bandwidth expansion to leverage the extended reach and enhanced user capacity and considered as a good solution to the bandwidth requirement for future access networks, with potential for higher data rate, improved data security. The receiver sensitivities of M-ary DPPM about $-51.4 \mathrm{dBm}$ ( 21.9 photons/bit) (CB), and $-51.5 \mathrm{dBm}$ (21.4 photons/bit, MCB) can be achieved, which implies an improvement when compared with an OOK-NRZ system $(\sim 38$ photons/bit $)$ in the non-turbulent atmospheric condition. M-ary DPPM retains its sensitivity improvement over OOK even in the existence of crosstalk while predicting a lower power penalty of about $0.2-3.0 \mathrm{~dB}$ for weak turbulence at low coding level (M) 2 in WDM systems.
\end{abstract}

Keywords: Amplified spontaneous emission (ASE) noise; Interchannel crosstalk; Wavelength division multiplexing (WDM) systems/PON; M-ary digital pulse-position modulation (M-ary DPPM); Freespace optical (FSO) communications; Modified Chernoff bound (MCB)

\section{Introduction}

One of the popular modulation schemes widely applied in free-space optical (FSO) communications is digital pulse-position modulation (DPPM) [1,2]. This scheme is well known to be attractive in different FSO environments including inter-satellite, atmospheric, and indoor wireless channels [1-3]. Apart from the power efficiency advantage, there is the additional advantage that there is no need to set and track a decision threshold in many DPPM systems [4, 5]. DPPM has been proposed and intensively investigated for optical fiber systems [5, 6-8], however, DPPM is particularly attractive in an FSO channel relative to an optical fiber channel because the FSO channel is dispersion free [1, 5, 8]. The advantages of DPPM however do come at the expense of bandwidth expansion, but with a moderately low coding level, DPPM can combine with most multiplexing/multiple access techniques 
without considerable bandwidth expansion [8,9]. Also, some hybrids of DPPM with other modulation schemes such as phase-shift keying and frequency-shift keying have been proposed for point-to-point fiber communication systems $[5,8,9]$ and could be alternative options to improve the DPPM bandwidth efficiency. With the availability of bandwidth-intensive services such as video on demand (VoD), Internet protocol television (IPTV), IP telephony, and interactive gaming/videoconferencing, there has been a rapid rise in bandwidth demand from users [5, 10-12]. In response to this increase in bandwidth demand, wavelength division multiplexing (WDM) and dense WDM (DWDM) systems have been investigated and/or deployed for optical fiber, atmospheric and indoor wireless optical networks [8, 9, 13-15]. WDM could also be applied in multiple user access networks. For example, WDM passive optical network $(\mathrm{PON})$ is generally considered as a good solution to the bandwidth requirement for future access networks, with the potential for higher data rate, improved data security, and longer reach $[8,9,13,16]$. WDM system has application in both optical fiber and FSO systems [8, 9, 17-19]. With WDM-PON, fixed wavelengths are assigned to each optical network unit (ONU), thus more fully exploiting the hightransmission bandwidth available in the optical domain and avoiding the synchronization and threshold acquisition required in the burst mode upstream of time-division multiplexing/time division multiple access (TDM/TDMA) systems [5, 8, 9, 20, 21]. The application of optical pre-amplification to overcome the impact of receiver thermal noise is one way of improving the receiver sensitivity of FSO systems. Aside from the optical gain, the optical pre-amplifier also generates amplified spontaneous emission (ASE) noise which, in turn, generates additional beat noises (spontaneous-spontaneous and signalspontaneous) in the electrical domain at the receiver. The overall electrical domain noise is non-Gaussian, although it has often been approximated as Gaussian in probability density functions (pdfs) used for describing binary signals dominated by ASE noise $[22,23]$. The moment generating function (MGF) represents a convenient statistical way of describing the signal plus ASE noise in a system employing an optically pre-amplified receiver while Chernoff bound (CB) and modified Chernoff bound (MCB) are techniques that use this description to obtain upper bounds upon the bit-error-rate (BER) $[5,8,9,24,25]$. The reminder paper is organized as follows: Section 2 describes the system design and modeling for optically pre-amplified WDM-DPPM in the FSO communication system. Section 3 introduces the biterror-rate (BER) analysis. Section 4 discusses the BER evaluation for hybrid WDM-PON /FSO systems Section 5 presents the calculation results and discussion. Section 6 summarizes our observations and discusses potential future extensions of the research.

\section{Materials and methods}

\section{System description and model}

In the DPPM signal transmission scheme, a frame of duration equal to $\mathrm{MT}_{\mathrm{b}}$ is divided into $\mathrm{n}=2^{\mathrm{M}}$ equal time slots of length $t_{s}=M_{b} / n$, where $M$ is the coding level and equal to the number of data bits transmitted per DPPM frame, $T_{b}=1 / R_{b}$ is the equivalent on-off keying non-return-to-zero (OOK-NRZ) bit period and $\mathrm{R}_{\mathrm{b}}$ is the data rate [9]. The maximum likelihood detection receiver is preferred for the best performance in DPPM FSO systems [1, 8, 9]. The decision circuitry is required to integrate over each slot in a frame and the decision is made by comparing the results and selecting the slot with the largest signal as the pulse position $[4,5]$. Therefore faster electronic processing speed is required compared to the threshold method used in OOK systems. A general WDM-DPPM system that might require evaluation of crosstalk impact could include a fiber or free space (or hybrid) system and maybe in a point-to-point, multipoint-to-point, or PON configuration [9]. Different sources and levels of crosstalk could arise in a DWDM DPPM system depending on the link configuration. In most point-to-point systems with all signal wavelengths originating from the same place, the major source of crosstalk is imperfect optical band-pass filter (OBPF)/demultiplexer (demux) rejection and since most realistic systems will employ OBPF/demux with good rejection ratio [5, 8-10]. But in multipoint-to-point links such as upstream transmission in hybrid fiber free-space optical (HFFSO) systems as shown in Fig. 1 (a) or in PON where signals could experience asymmetric splitting loss, fiber and/or FSO attenuation, beam spreading, and coupling loss, signals at different wavelengths will arrive at the OBPF/demux at different power levels. A 
generic system structure that could be easily adapted to all the different scenarios above is shown in Fig. 1 (b) [9]. DPPM signals from different wavelengths are multiplexed and transmitted over an FSO link to a receiving lens (not shown They could also in principle arise from different physical locations as long as they can be collected and coupled effectively into the optical amplifier (OA) which is done by collimating them into a short fiber length at the amplifier input before being demultiplexed into different wavelengths for detection by a positive-intrinsic-negative (PIN) photodiode [9]. The optical preamplifier is just treated as a linear gain block generating noise as in Fig. 1 (b).

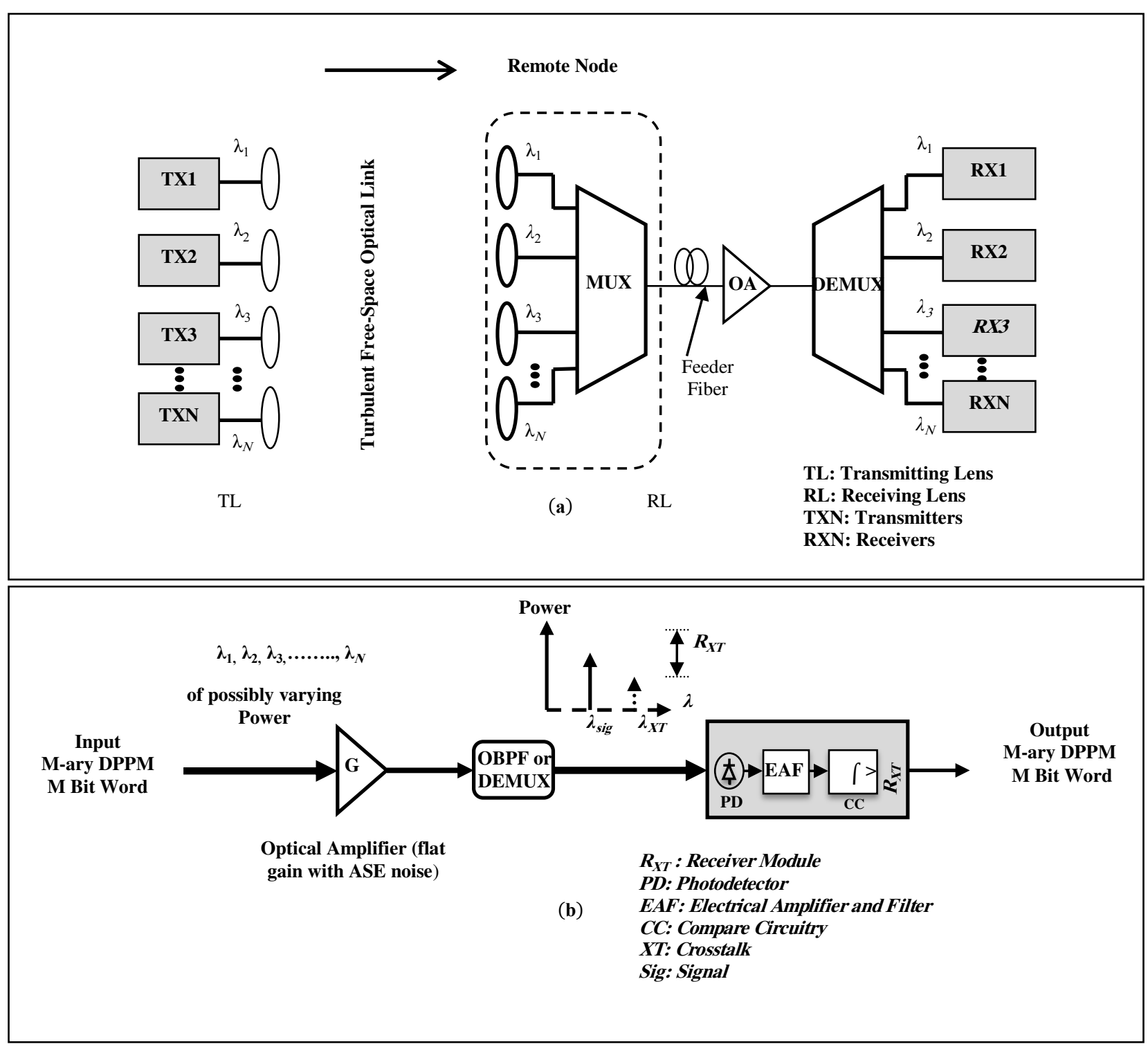

Figure 1 Structure for optically pre-amplified WDM/M-ary DPPM scheme of PON-HFFSO system: (a) Specific system architecture for crosstalk evaluation and (b) Generic receiver system. We reproduced it from our previous publication in [9]. 


\section{M-ary DPPM scheme modeling}

The analysis of crosstalk in a DPPM system requires some consideration to ensure that the different scenarios that could arise during frame reception are taken into account. For example, there may be an alignment of frames and slots or only slots between the signal and crosstalk (XT) as shown in Fig. 2 (a) and (b) respectively [5, 8, 9]. In Fig. 2, the case where signal and crosstalk frames are aligned is referred to as frames aligned (FA) Fig. 2 (a), the case where the signal and crosstalk have only their slots aligned is referred to as only slots aligned (OSA) Fig. 2 (b) while the case where there is a misalignment between the signal and crosstalk slots is referred to as slots misaligned (SMis) Fig. 2 (c). The moment generating function (MGF) describing the random variable of the current $Y_{\text {sig }}(\Delta t)$ where sig $\in\{0,1\}$ depending on pulse transmitted or not, $\Delta \mathrm{t}$ is the duration of the crosstalk pulse overlap with the slot under consideration) for a general slot which contains ASE, possibly a signal pulse and possibly a single XT pulse (or some fraction of one) is derived using the same treatment as [5, 9, 24, 26, 27]. It is written as:

$\mathrm{M}_{\mathrm{Y}_{\mathrm{sig}}(\Delta \mathrm{t})}(\mathrm{s})=\left\{\frac{R^{\prime} G\left(e^{s q / t_{s}}-1\right) \int_{t_{s}} \operatorname{sig} P_{t r}(t) d t}{1-R^{\prime} N_{o}\left(e^{s q / t}-1\right)}\right\} \frac{\exp \left\{\frac{R_{i}^{\prime} G\left(e^{s q / t_{s}}-1\right) \int_{\Delta t} P_{X T}(t) d t}{1-R_{i}^{\prime} N_{o_{-X T}}\left(e^{s q / t_{s}}\right)}\right\}}{\left[1-R^{\prime} N_{o}\left(e^{s q / t_{s}}-1\right)\right]^{L}}$

where $\Delta t=t_{s}$ slots align with signal slots otherwise $t_{1}$ or $t_{2}$, and for no crosstalk in the slot, $\Delta t=0$. In addition, $\mathrm{P}_{\mathrm{tr}}$ and $\mathrm{P}_{\mathrm{XT}}$ are the DPPM rectangular pulse and the crosstalk pulse power respectively, both defined at the PD input, $R^{\prime}=\eta / h v_{i}, \eta$ is the PD quantum efficiency, $h$ is Planck's constant, $v$ and $v_{i}$ are the optical frequencies of the signal and crosstalk wavelengths respectively [5, 8-10], $q$ is the electron charge, $\mathrm{N}_{\mathrm{o}}=0.5(\mathrm{NF} \times \mathrm{G}-1) h v$ is the single polarization ASE power spectral density (PSD) at the amplifier output (and also at the PD input if demultiplexer nominal loss is neglected), G and NF are the optical amplifier gain and noise figure respectively, $L=B_{o} m_{t} t_{s}$ is the product of spatial and temporal modes $[2,8,9], \mathrm{B}_{\mathrm{o}}$ is the demux channel optical noise bandwidth and $m_{t}$ is the number of ASE noise polarisation states. $\mathrm{N}_{\mathrm{o}_{-} \mathrm{XT}}$ is the ASE PSD at the photodetector at crosstalk wavelength and $\mathrm{C}_{\mathrm{XT}}=$ $\mathrm{P}_{\mathrm{tr}} / \mathrm{P}_{\mathrm{XT}}$ is the signal-to-crosstalk ratio, fixed at the output of the demux.

The MGF has been modified to account for crosstalk-ASE beat noise assuming the crosstalk and the desired signal experiences the same ASE noise at the amplifier output $[9,10,28]$. The overall MGF including the zero-mean Gaussian thermal noise is given as $[5,9]$

$$
\mathrm{M}_{\mathrm{Y}_{\mathrm{Sig}}(\Delta t)}(\mathrm{s})=\mathrm{M}_{\mathrm{Y}_{\mathrm{sig}}(\Delta t)}(\mathrm{s}) \exp \left(\frac{\mathrm{s}^{2} \sigma_{\mathrm{th}}^{2}-\mathrm{DPPM}}{2}\right)
$$

where $\sigma_{\text {th-DPPM }}^{2}$ is the DPPM thermal noise variance. Following [1, 2, 8-10], the means and variances of the random variables representing the integration over the slot that contains only the signal pulse, only crosstalk pulse, both signal and crosstalk pulses, and no pulses (i.e. empty slot) are derived from the overall MGF, through its first and second derivatives respectively, with s set equal to 0 . They are respectively generally written as $[5,9,10,29]$

$$
\mu_{Y_{s i g}(\Delta t)}(s)=\frac{L R^{\prime} q N_{o}}{t_{s}}+R^{\prime} G q\left(\operatorname{sig} P_{t r} \frac{P_{X T} \Delta t}{t_{s}}\right)
$$




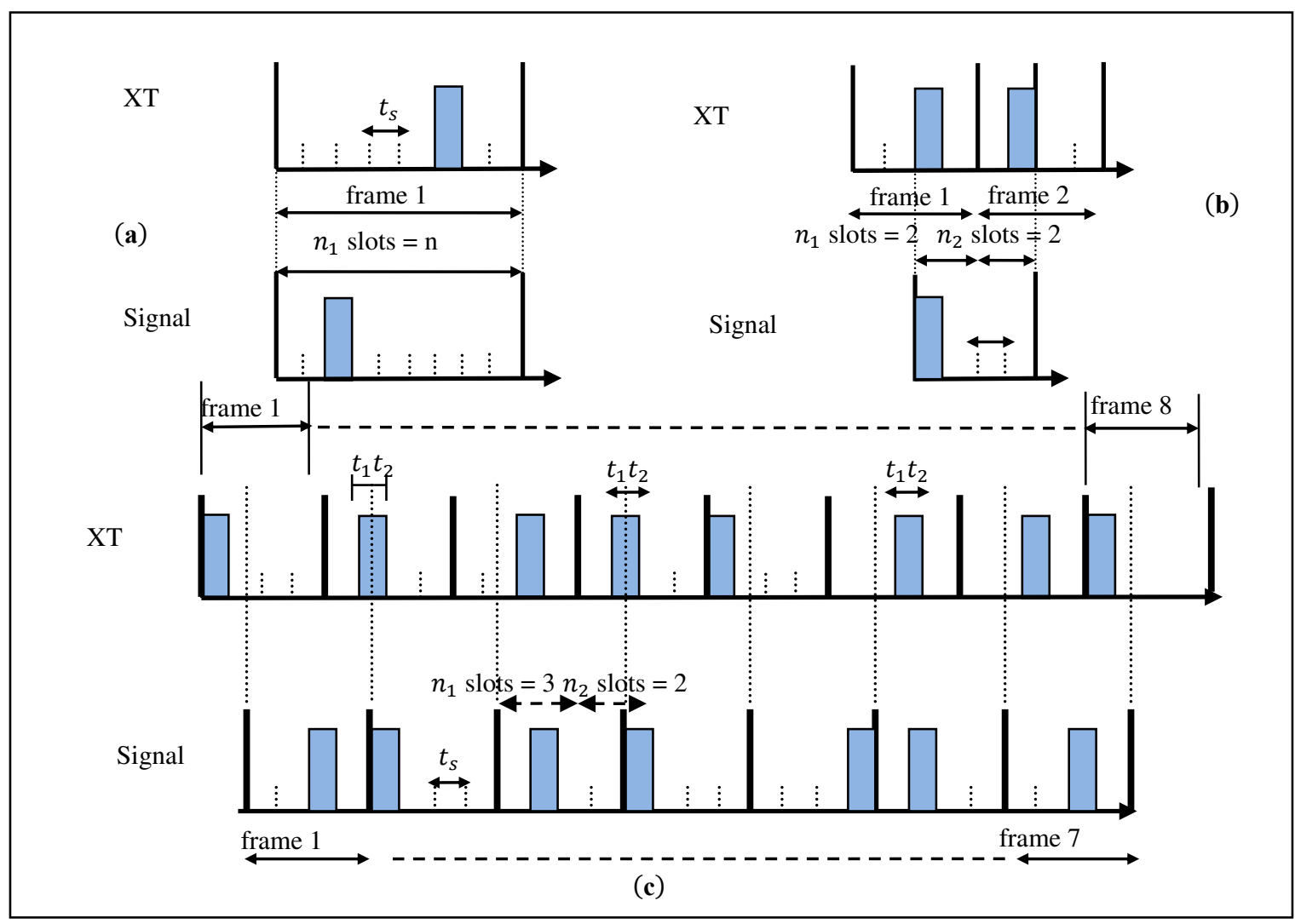

Figure 2 Illustration of crosstalk in WDM-M-ary DPPM receiver: (a) Frames aligned (FA) for M = 3, (b) Only slots aligned (OSA) for $\mathrm{M}=2$ and (c) Slots (and frames) misaligned (SMis) for $\mathrm{M}=2$.

$$
\begin{gathered}
\sigma_{X_{s i g}(\Delta t)}^{2}=\sigma_{t h-D P P M}^{2}+\left(\frac{L R^{\prime} q^{2} N_{o}\left(1+R^{\prime} N_{o}\right)}{t_{s}^{2}}\right)+R^{\prime} G q^{2}\left[\left(1+2 R^{\prime} N_{o}\right) \frac{s i g P_{t r}}{t_{s}}\right] \\
+R_{i}^{\prime} G q^{2}\left[\left(1+2 R_{i}^{\prime} N_{o_{X T}}\right) \frac{P_{X T} \Delta t}{t_{s}^{2}}\right]
\end{gathered}
$$

Given that each symbol has an equal probability of being transmitted in a slot, the probability that a symbol is successfully received in the presence of crosstalk $P_{w s\left(I_{i-} r_{i}\right)}=1-P_{w e\left(I_{i-} r_{i}\right)}$ where $P_{w e\left(I_{i-} r_{i}\right)}$ is the symbol error probability in the presence of crosstalk, $r_{i}$ and $I_{i}(i \in\{s, 1,2\})$ denote the number of crosstalk (of duration $t_{s}, t_{1}$ or $t_{2}$ occurring in the signal pulse slot and signal frame respectively. Thus for single crosstalk case, $\left(r_{i} \in\{0,1\}\right)$ while $\left(I_{i} \in\{0,1,2\}\right)$. Following the same treatment as [1], one can write that:

$P_{w s\left(I_{i}-r_{i}\right)} \geq \prod_{\substack{j=1 \\ j \neq s i g s l o t}}^{n} P\left(X_{1}(\Delta t)>X_{j}\right)$

where $X_{j}$ represents the content of the non-signal slot $X_{o}\left(\Delta t_{j}\right)$ and $\Delta t_{j}$ is the crosstalk overlap with the $\mathrm{j}^{\text {th }}$ (empty) slot. Assuming that the random variables $X_{1}(\Delta t)$ and $X_{0}(\Delta t)$ are Gaussian, the 
expression $P\left\{X_{o}\left(\Delta t_{j}\right)>X_{1}(\Delta t)\right\}$ using the Gaussian approximation (GA) of the ASE beat noises, is of the general form $[1,2,5,9,10,29]$

$$
P\left\{X_{o}\left(\Delta t_{j}\right)>X_{1}(\Delta t)\right\}=0.5 \operatorname{erfc}\left(\frac{\mu_{X_{1}(\Delta t)}-\mu_{X_{0}\left(\Delta t_{j}\right)}}{\sqrt{2\left(\sigma_{X_{1}(\Delta t)}^{2}+\sigma_{X_{0}\left(\Delta t_{j}\right)}^{2}\right)}}\right)
$$

For the Chernoff bound (CB) we have that the general form for random variable $\mathrm{X}$ and a fixed threshold $T_{t h}$ is $P\left(X>T_{t h}\right) \leq E\left\{\exp \left[s\left(X-T_{t h}\right)\right]\right\}, \mathrm{s}>0$. Thus $\left(\mathrm{P}>T_{t h} \leq M_{X}(s) e^{-s T_{t h}}\right)$, and manipulation of this for the difference of two random variables implies that $[5,9,29]$

$$
P\left\{X_{o}\left(\Delta t_{j}\right)>X_{1}(\Delta t)\right\} \leq M_{X_{1}(\Delta t)}(-s) M_{X_{0}(\Delta t)}(s) \quad(s>0)
$$

For the modified Chernoff bound (MCB) [2, 5], $P\left(X>T_{t h}\right) \leq M_{X}(s) e^{-s T_{t h}} / s \sigma_{t h} \sqrt{\pi}[5,9,10]$. Modifying this inequality for the difference of two random variables for $X_{o}\left(\Delta t_{j}\right)$ and $X_{1}(\Delta t)$ which both have the same thermal noise contribution then yields, [1, 2, 5, 9, 29]

$P\left\{X_{o}\left(\Delta t_{j}\right)>X_{1}(\Delta t)\right\} \leq \frac{M_{X_{1}(\Delta t)}(-s) M_{X_{0}(\Delta t)}(s)}{2 s \sigma_{t h} \sqrt{\pi}} \quad(s>0)$

For the FA and OSA cases the symbol error probability in the presence of a specific crosstalk combination is written as $[1,9,10]$

$P_{w e\left(I_{s}-r_{s}\right)} \leq 1-\left[1-P\left\{X_{o}(0)>X_{1}(\Delta t)\right\}\right]^{n-1\left(I_{s}-r_{s}\right)}\left[1-P\left\{X_{o}\left(t_{s}\right)>X_{1}(\Delta t)\right\}\right]^{I_{s}-r_{s}}$

(9)

where $I_{s}$ and $r_{s}$ are the number of crosstalk of duration $t_{s}$ occurring in the signal frame and signal pulse slot respectively, $\Delta t=t_{s}$ if crosstalk hits signal pulse slot, otherwise $\Delta \mathrm{t}=0$. Similarly, the symbol error probability in the presence of crosstalk for the slot misaligned (SMis) case is written as,

$$
\begin{aligned}
& P_{w e\left(I_{1}, I_{2}-r_{1}, r_{2}\right)} \leq 1-\left[1-P\left\{X_{o}(0)>X_{1}(\Delta t)\right\}\right]^{n-1-\ddot{\chi}}\left[1-P\left\{X_{o}\left(t_{1}\right)>X_{1}(\Delta t)\right\}\right]^{I_{1}-r_{1}} \\
& {\left[1-P\left\{X_{o}\left(t_{2}\right)>X_{1}(\Delta t)\right\}\right]^{I_{2}-r_{2}}}
\end{aligned}
$$

where $I_{1}, I_{2}$ and $r_{1}, r_{2}$ are the number of crosstalk of duration $t_{1}, t_{2}$, occurring in the signal frame and signal pulse slot respectively, $\ddot{\chi}=I_{1}+I_{2}, \Delta t=t_{1}$ or $t_{2}$ if crosstalk of duration $t_{1}$ or $t_{2}$ respectively hits the signal pulse slot, otherwise $\Delta \mathrm{t}=0$.

\section{Atmospheric turbulence model}

Atmospheric scintillation occurs due to the temperature difference between the earth's surface and atmosphere induced refractive index changes of the air along with the optical link [8], causing rapid fluctuation of the received signal, deviation in the degree of coherence of the optical signal, and also poor BER $[8,9]$. These effects of turbulence, weak, moderate, and strong are characterized using the gammagamma (GG) distribution probability density function (pdf) is given as $[5,8,9,29-34]$

$p_{\mathrm{GG}}\left(h_{Z}\right)=\frac{2(\alpha \beta)^{(\alpha+\beta) / 2}}{\Gamma(\alpha) \Gamma(\beta)} h_{Z}^{((\alpha+\beta) / 2)-1} K_{\alpha-\beta}\left(2 \sqrt{\alpha \beta h_{Z}}\right) ; h_{Z}>0$, 
where $\mathrm{h}_{\mathrm{z}}$ is the attenuation due to atmospheric turbulence for the signal $\left(\mathrm{h}_{\mathrm{sig}}\right)$ or interfere $\left(\mathrm{h}_{\text {int }}\right), \alpha$ and $\beta$ are the effective numbers of large-scale and small-scale eddies of the scattering process, respectively, $\mathrm{K}_{\mathrm{n}}(\cdot)$ is a modified Bessel function (second kind, order $n$ ), and $\Gamma(\cdot)$ is the gamma function [8-10]. The signal and interferer travel over physically distinct paths in the upstream and thus have uncorrelated turbulence; hence, their GG pdfs are each treated independently. The parameter $\alpha$ and $\beta$ for plane-wave propagation for arbitrary aperture size are given as $[5,8-10,29-34]$

Table 1 Typical parameters for characterizing weak-to saturated turbulence regimes [5, 8-10, 31, 35].

\begin{tabular}{ccccc}
\hline \multirow{2}{*}{ Parameter } & \multicolumn{5}{c}{ Turbulence Regimes } \\
\cline { 2 - 5 } & $\begin{array}{r}\text { Weak } \\
\left(\sigma_{\mathrm{R}}^{2}<1\right)\end{array}$ & $\begin{array}{c}\text { Moderate } \\
\left(\sigma_{\mathrm{R}}^{2} \approx 1\right)\end{array}$ & $\begin{array}{c}\text { Strong } \\
\left(\sigma_{\mathrm{R}}^{2}>1\right)\end{array}$ & $\begin{array}{c}\text { Saturated } \\
\left(\sigma_{\mathrm{R}}^{2} \rightarrow \infty\right)\end{array}$ \\
\hline$\sigma_{\mathrm{R}}^{2}$ & 0.2 & 1.6 & 3.5 & 25 \\
$\alpha$ & 11.651 & 4.027 & 4.226 & 8.048 \\
$\beta$ & 10.122 & 1.911 & 1.362 & 1.032 \\
\hline
\end{tabular}

$\alpha=\left\{\exp \left[\frac{0.49 \sigma_{\mathrm{R}}^{2}}{\left(1+0.65 \mathrm{~d}^{2}+1.11 \sigma_{\mathrm{R}}^{12 / 5}\right)^{7 / 6}}\right]-1\right\}^{-1}$,

$\beta=\left\{\exp \left[\frac{0.51 \sigma_{\mathrm{R}}^{2}\left(1+0.69 \sigma_{\mathrm{R}}^{12 / 5}\right)^{-5 / 6}}{1+0.9 \mathrm{~d}^{2}+0.62 \mathrm{~d}^{2} \sigma_{\mathrm{R}}^{12 / 5}}\right]-1\right\}^{-1}$,

$d=\sqrt{\mathrm{kD}_{\mathrm{RX}}^{2} / 4 l_{\mathrm{fso}}}$

where $d$ is the normalized receiver collecting lenses (RCLs) [8-10,30,33], $\mathrm{C}_{\mathrm{n}}^{2}$ is the refractive index structure constant (ranging from $\approx 10^{-17} \mathrm{~m}^{-2 / 3}$ to $\approx 10^{-13} \mathrm{~m}^{-2 / 3}$ ), $l_{\text {fso }}$ is the FSO link length, $k=2 \pi / \lambda$ is the wave-number, and $\lambda$ is the wavelength [29,30,33]. Typical values of $\sigma_{\mathrm{R}}^{2}, \alpha$, and $\beta$ used for modeling weak, moderate, strong, and saturated turbulence regimes are shown in Table $1[5,8-10,31$, 35]. The Rytov variance distinguishes the various link turbulence regimes $\sigma_{\mathrm{R}}^{2}$ if the resulting $\sigma_{\mathrm{R}}^{2}<1$, we have weak turbulence (WT) [8-10]; if $\sigma_{\mathrm{R}}^{2} \approx 1$, we have moderate turbulence (MT), and if $\sigma_{R}^{2}>1$; we have strong turbulence (ST), and if saturated turbulence $\sigma_{R}^{2} \rightarrow \infty$ are given as from [8-10, $30-34]$ 


$$
\sigma_{\mathrm{R}}^{2}=1.23 \mathrm{C}_{\mathrm{n}}^{2} \mathrm{k}^{7 / 6} l_{\mathrm{fso}}^{11 / 6}
$$

\section{BER analysis}

The number of other crosstalk combinations taking place in the signal frame increases with slot misalignment, with the specific analysis becoming upset. Considering Fig. 2 (c) with $n_{1}+n_{2}=n+1$. Fig. 3 below shows crosstalk plotted against the channel numbers using the WDM system. Here we determined crosstalk from the Eq. (16)

$$
\sigma^{2}=M^{\prime} B^{2} R_{d}^{2} P_{s}^{2}\left[2 \varepsilon_{\text {adj }}+(N-3) \varepsilon_{\text {nonadj }}+X_{\text {switch }}\right]
$$

where, $M^{\prime}=$ number of hop, $B=$ bit ratio of signal peak power, $R_{d}=$ detector resistance and $P_{s}=$ input power, $\varepsilon=$ effective adjacent and effective nonadjacent, $N=$ number of channel, $X=$ switch values, taken for Fig. 3, $\mathrm{B}=1, \mathrm{R}_{\mathrm{d}}=0.85, \mathrm{X}=1$. It can be said that if we increase the hops number then crosstalk also increases. Another way, it can be analyzed that for a fixed number of crosstalks if we use more hops, the number of channel decrease and in another way, we can use more channels for fewer hops as seen in Fig. 3. The bit error rate contribution when there is no crosstalk is written as

$$
\operatorname{BER}\left(\mathrm{n}_{1}\right)=\mathrm{p}_{\mathrm{f}(0,0)}\left(\mathrm{n}_{1}\right) \frac{\mathrm{n}}{2(\mathrm{n}-1)} \mathrm{P}_{\mathrm{we}\left(0,0 \_0,0\right)}
$$

While for the other possibilities, it is generally written as [1, 2, 29]:

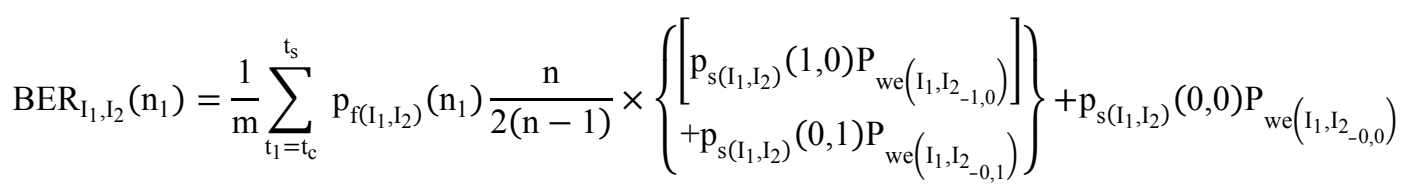

The overall BER in the presence of crosstalk for slots misaligned is calculated by computing up all the error contributions calculated from Eqs. (17) and (18) is given as [1, 2, 29]

$$
\operatorname{BER}=\frac{1}{\mathrm{n}} \sum_{\mathrm{n}_{1}=1}^{\mathrm{n}}\left\{\begin{array}{c}
\operatorname{BER}\left(\mathrm{n}_{1}\right)+\mathrm{BER}_{0,1}\left(\mathrm{n}_{1}\right)+\mathrm{BER}_{1,0}\left(\mathrm{n}_{1}\right) \\
+\sum_{\mathrm{I}_{1}=1}^{2}\left[\operatorname{BER}_{\mathrm{I}_{1}, 1}\left(\mathrm{n}_{1}\right)+\mathrm{BER}_{\mathrm{I}_{1}, 2}\left(\mathrm{n}_{1}\right)\right]
\end{array}\right\}
$$

As shown in Fig. 4, for values of $m \geq 100$, the target BER of $10^{-10}$ is achieved while the BER becomes worse for $\mathrm{m} \leq 100$, specifically for lower coding levels and higher crosstalk power. For definiteness, $\mathrm{m}$ $=100$ is used in the calculations, as seen in Fig.4, higher values of $\mathrm{m}$ do not show any significant change on the BER, but rather increases the computational time. The OSA case is recovered for $\mathrm{m}=1$, although a higher received power than those used in Fig. 4 would be required to attain the BER of $10^{-10}$. 


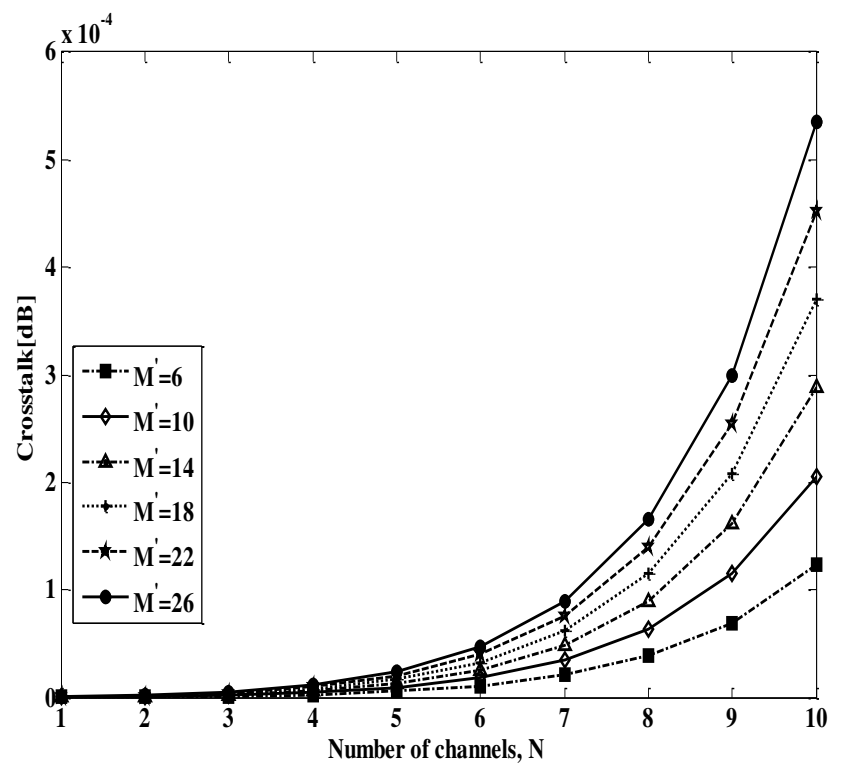

Figure 3 Crosstalk vs. the number of channels.

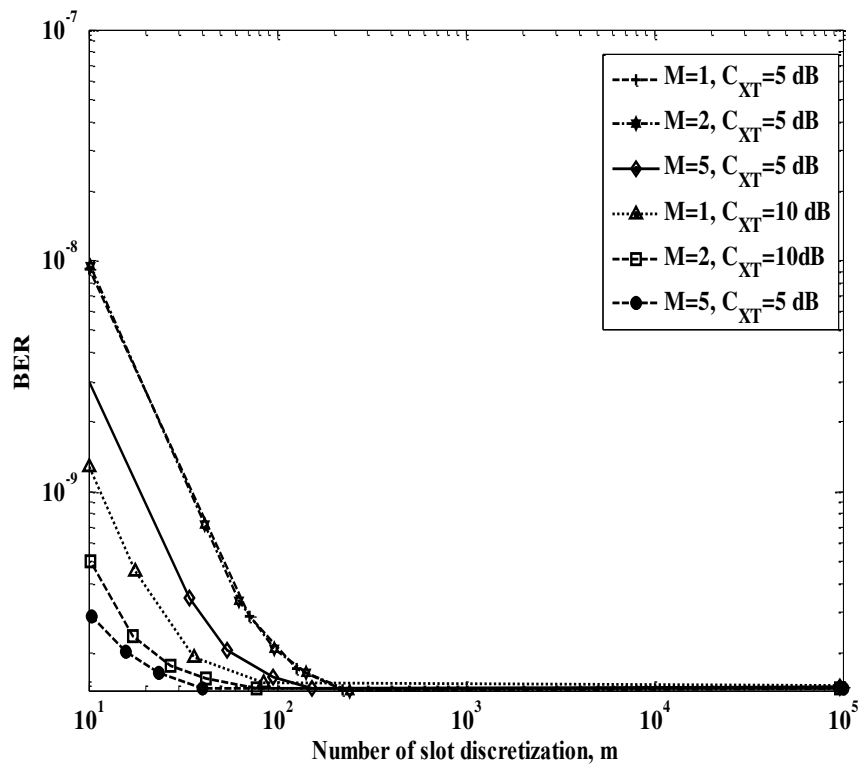

Figure 4 BER as a function of the number of slot discretization (m) for SMis using MCB, $\mathrm{G}=30 \mathrm{~dB}$, for single crosstalk with a received power corresponding to $\mathrm{BER}=10^{-10}$, ( $\mathrm{m}$ is a dimensionless modeling artifact. 


\section{Downstream analysis}

For the downstream transmission, $\mathrm{I}_{\text {sig }}$ and $\mathrm{I}_{\text {int }}$ can be expressed as $[5,10,15]$

$$
\left[\begin{array}{c}
\mathrm{I}_{\text {sig }} \\
\mathrm{I}_{\text {int }}
\end{array}\right]=\left[\begin{array}{c}
R \mathrm{P}_{\mathrm{t}, \text { sig }}\left(\prod_{\mathrm{i}=1}^{\mathrm{N}} \mathrm{G}_{\mathrm{i}} \mathrm{h}_{\mathrm{i}}^{\mathrm{l}} \mathrm{h}_{\mathrm{i}}^{\mathrm{a}}\right) \mathrm{h}_{\mathrm{N}+1}^{1} \mathrm{~h}_{\mathrm{N}+1}^{\mathrm{a}} \mathrm{L}_{\text {mux }} \mathrm{L}_{\text {demux }} \\
R \mathrm{P}_{\mathrm{t}, \text { int }}\left(\prod_{\mathrm{i}=1}^{\mathrm{N}} \mathrm{G}_{\mathrm{i}} \mathrm{h}_{\mathrm{i}}^{\mathrm{l}} \mathrm{h}_{\mathrm{i}}^{\mathrm{a}}\right) \mathrm{h}_{\mathrm{N}+1}^{1} \mathrm{~h}_{\mathrm{N}+1}^{\mathrm{a}} \mathrm{L}_{\text {mux }} \mathrm{L}_{\text {demux }} \mathrm{L}_{\text {demux }, \mathrm{XT}}
\end{array}\right],
$$

where $R$ is the responsivity of the PIN photodiode, $G_{\mathrm{i}}$ is the optical amplifier fixed-gain at the $i$-th relay (assuming that $\mathrm{G}_{1}=\cdots=\mathrm{G}_{\mathrm{i}} \cdots=\mathrm{G}_{\mathrm{N}}$ ). SNR is the electrical signal to noise ratio in the case of DPPM signaling, which is defined as $[10,31]$

$\operatorname{SNR}=\frac{\left(\mu_{0}-\mu_{u}\right)^{2}}{\sigma_{0}^{2}+\sigma_{u}^{2}}$

In (21) $\sigma_{0}^{2}$ and $\sigma_{\mathrm{u}}^{2}$ are receiver noise variances of signal currents in 0 and $u$ slots, which can be expressed as $[15,31]$

$\left[\begin{array}{c}\sigma_{0}^{2} \\ \sigma_{\mathrm{u}}^{2}\end{array}\right]=\left[\begin{array}{c}\sigma_{\mathrm{sig}}^{2}+\sigma_{i n t}^{2}+\sigma_{\mathrm{z}, \mathrm{r}}^{2}+\sigma_{\mathrm{ASE}, \mathrm{r}}^{2}+\sigma_{\mathrm{z,c}}^{2}+\sigma_{\mathrm{ASE}, \mathrm{c}}^{2}+\sigma_{\mathrm{T}}^{2} \\ \sigma_{\mathrm{int}}^{2}+\sigma_{\mathrm{z}, \mathrm{r}}^{2}+\sigma_{\mathrm{ASE}, \mathrm{r}}^{2}+\sigma_{\mathrm{z}, \mathrm{c}}^{2}+\sigma_{\mathrm{ASE}, \mathrm{c}}^{2}+\sigma_{\mathrm{T}}^{2}\end{array}\right]$

where $\sigma_{\mathrm{sig}}^{2}, \sigma_{\mathrm{int}}^{2}, \sigma_{\mathrm{z}, \mathrm{r}}^{2}, \sigma_{\mathrm{ASE}, \mathrm{r}}^{2}, \sigma_{\mathrm{z}, \mathrm{c}}^{2}, \sigma_{\mathrm{ASE}, \mathrm{c}}^{2}, \sigma_{\mathrm{T}}^{2}$ are variances of signal shot noise, interferer shot noise, accumulated amplified background noise over multiple relays, accumulated amplified ASE noise over multiple relays $(\mathrm{N})$, background noise at the destination, ASE noise resulted from the amplifier at the RN received at the destination, and receiver thermal noise, respectively $[10,31] \cdot \mu_{0}=I_{\text {sig }}+I_{\text {int }}$ and $\mu_{u}=I_{\text {int }}$ are respectively the mean values of signal currents in 0 and $u$ slots, in which $\mathrm{I}_{\text {sig }}$ and $\mathrm{I}_{\text {int }}$ are the signals and interferer currents. Since the atmospheric turbulence in the $(N+1)$-th hop is treated similarly in the downstream direction and independently in the upstream direction for the signal and interferer, the calculation of signal and interferer currents as well as receiver noise variances is derived differently [31]. In Eq. (22), the variances of receiver noises can be expressed as [2, 10, 15, 31]

$$
\begin{aligned}
& \sigma_{\text {sig }}^{2}=2 \mathrm{qRP}_{\mathrm{t}, \mathrm{sig}}\left(\prod_{\mathrm{i}=1}^{\mathrm{N}} \mathrm{G}_{\mathrm{i}} \mathrm{h}_{\mathrm{i}}^{\mathrm{l}_{\mathrm{i}}^{\mathrm{a}}}\right) \mathrm{h}_{\mathrm{N}+1}^{1} \mathrm{~h}_{\mathrm{N}+1}^{\mathrm{a}} \mathrm{L}_{\text {mux }} \mathrm{L}_{\text {demux }} \mathrm{B}_{\mathrm{e}}, \\
& \sigma_{\text {int }}^{2}=2 q R P_{t, \text { int }}\left(\prod_{i=1}^{\mathrm{N}} \mathrm{G}_{\mathrm{i}} \mathrm{h}_{\mathrm{i}}^{\mathrm{l}} \mathrm{h}_{\mathrm{i}}^{\mathrm{a}}\right) \mathrm{h}_{\mathrm{N}+1}^{1} \mathrm{~h}_{\mathrm{N}+1}^{\mathrm{a}} \mathrm{L}_{\text {mux }} \mathrm{L}_{\text {demux }} \mathrm{L}_{\text {demux }, \mathrm{XT}} \mathrm{B}_{\mathrm{e}} \text {, } \\
& \sigma_{z, \mathrm{r}}^{2}=2 \mathrm{qR}\left(\sum_{\mathrm{i}=1}^{\mathrm{N}} \prod_{\mathrm{k}=\mathrm{i}}^{\mathrm{N}} \mathrm{G}_{\mathrm{k}} \mathrm{h}_{\mathrm{k}+1}^{1} \mathrm{~h}_{\mathrm{k}+1}^{\mathrm{a}}\right) \mathrm{L}_{\text {demux }} \mathrm{B}_{\mathrm{e}} \\
& \sigma_{\mathrm{ASE}, \mathrm{r}}^{2}=2 \mathrm{qR}\left(\sum_{\mathrm{i}=1}^{\mathrm{N}-1} \prod_{\mathrm{k}=\mathrm{i}+1}^{\mathrm{N}} \mathrm{G}_{\mathrm{k}} \mathrm{h}_{\mathrm{k}}^{1} \mathrm{~h}_{\mathrm{k}}^{\mathrm{a}} \mathrm{h}_{\mathrm{N}+1}^{1} \mathrm{~h}_{\mathrm{N}+1}^{\mathrm{a}}\right) \mathrm{L}_{\mathrm{demux}} \mathrm{B}_{\mathrm{e}}, \\
& \sigma_{\mathrm{ASE}, \mathrm{c}}^{2}=2 \mathrm{qRP} \mathrm{A}_{\mathrm{N}+1}^{\mathrm{N}} \mathrm{h}_{\mathrm{N}+1}^{1} \mathrm{~h}_{\mathrm{N}+1}^{\mathrm{a}} \mathrm{L}_{\text {demux }} \mathrm{B}_{\mathrm{e}} \text {, }
\end{aligned}
$$


$\sigma_{\mathrm{z}, \mathrm{c}}^{2}=2 \mathrm{qRP} \mathrm{b}_{\mathrm{e}}$,

$\sigma_{\mathrm{T}}^{2}=\frac{4 \mathrm{k}_{\mathrm{B}} \mathrm{T}}{\mathrm{R}_{\mathrm{L}}} \mathrm{B}_{\mathrm{e}}$

where $q$ is the electron charge; $k_{B}$ is the Boltzmann's constant [10]; $T$ is the absolute temperature; $\mathrm{R}_{\mathrm{L}}$ the load resistance; $B_{e}$ is the effective noise bandwidth defined as $\mathrm{B}_{\mathrm{e}}=\frac{1}{\mathrm{~T}_{\mathrm{s}}}=\frac{\mathrm{MR}_{\mathrm{b}}}{\log _{2}(\mathrm{M})} ; \mathrm{P}_{\mathrm{A}}^{\mathrm{i}}$ is the average power of ASE noise at the $i$-th relay, assuming that $\mathrm{P}_{\mathrm{A}}^{1}=\cdots=\mathrm{P}_{\mathrm{A}}^{\mathrm{i}}=\cdots=\mathrm{P}_{\mathrm{A}}^{\mathrm{N}}$. For performance calculations it is assumed to have signal mux/demux loss $\mathrm{L}_{\text {mux }}$ and $\mathrm{L}_{\text {demux }}(\leq 3.5 \mathrm{~dB})[10,15,31]$, adjacent channel additional loss $\mathrm{L}_{\text {mux.adj }}$ (typically $>30 \mathrm{~dB}$ ), and non-adjacent-channel additional loss $\mathrm{L}_{\text {mux.nonadj }}$ (typically $>35 \mathrm{~dB})[5,8-10,31]$. The channel states of $(N+1)$-th hop for signal and interferer are denoted as $\mathrm{h}_{\mathrm{N}+1, \mathrm{sig}}^{1} \mathrm{~h}_{\mathrm{N}+1}^{\mathrm{a}} \mathrm{L}_{\mathrm{mux}}$.

\section{Upstream Analysis}

By substituting $\mathrm{h}_{\mathrm{N}+1 \text {,sig }}^{1} \mathrm{~h}_{\mathrm{N}+1 \text {, sig }}^{\mathrm{a}}$ and $\mathrm{h}_{\mathrm{N}+1 \text {,int }}^{1} \mathrm{~h}_{\mathrm{N}+1 \text {, int }}^{\mathrm{a}}$ for $\mathrm{h}_{\mathrm{N}+1}^{1} \mathrm{~h}_{\mathrm{N}+1}^{\mathrm{a}}$ from Eqs. (20), (23), (24), we respectively obtain $\mathrm{I}_{\text {sig }}, \mathrm{I}_{\text {int }}$, and $\sigma_{\text {sig }}^{2}, \sigma_{\text {int }}^{2}$ for the upstream transmission. To obtain $\sigma_{\mathrm{ASE}, \mathrm{c}}^{2}, \mathrm{~h}_{\mathrm{N}+1}^{1}, \mathrm{~h}_{\mathrm{N}+1}^{\mathrm{a}}$ in Eq. (27) is replaced by $h_{1}=h_{1}^{1} h_{1}^{a}$ because this ASE noise experiences turbulence from the first hop when considering the direction from ONUs to the optical line terminator (OLT). For $\sigma_{\mathrm{z}, \mathrm{r}}^{2}, \sigma_{\mathrm{ASE}, \mathrm{r}}^{2}, \sigma_{\mathrm{z}, \mathrm{c}}^{2}, \sigma_{\mathrm{T}}^{2}$ the calculation is the same as in Eqs. (25), (26), (28), and (29), respectively [8 $\neg 10,31]$.

\section{BER evaluations for WDM-PON/FSO system}

The BER is the key performance attribute commonly used for FSO communication systems analysis $[5,36]$. By making a GA assumption for the noise, a BER, conditioned on the instantaneous loss (or gain) state of the turbulent channel $h_{t}$, is given as $[5,24]$

$\operatorname{BER}\left(\mathrm{P}_{\text {OAin }_{\mathrm{av}}}, h_{t}\right)=\frac{1}{2}\left[\frac{1}{2} \operatorname{erfc}\left(\frac{\mathrm{i}_{\mathrm{D}}-\mathrm{i}_{0}\left(\mathrm{P}_{\mathrm{OAin}_{\mathrm{av}}}, h_{t}\right)}{\sqrt{2 \sigma_{0}^{2}\left(\mathrm{P}_{\mathrm{OAin}_{\mathrm{av}}}, h_{t}\right)}}\right)+\frac{1}{2} \operatorname{erfc}\left(\frac{\mathrm{i}_{1}\left(\mathrm{P}_{\left.\mathrm{OAin}_{\mathrm{av}}, h_{t}\right)-\mathrm{i}_{\mathrm{D}}}\right.}{\sqrt{2 \sigma_{1}^{2}\left(\mathrm{P}_{\mathrm{OAin}_{\mathrm{av}}}, h_{t}\right)}}\right)\right]$

The optical signal power at the output of the optical amplifier $(\mathrm{OA})$ is obtained as

$P_{\text {out }}\left(P_{\text {in }}\right)=G\left(P_{\text {in }}\right) P_{\text {in }}$

Now, the non-adaptive decision threshold, assumed set to a long term average received power at the PD, can be obtained by statistically averaging (31) over the atmospheric turbulence pdf and it is obtained as $[2,5,8,9,15]$

$\mathrm{i}_{\mathrm{D}}\left(\mathrm{P}_{\mathrm{OAin}_{\mathrm{av}}}\right)=\mathrm{R} \int_{0}^{\infty} \mathrm{P}_{\text {out }}\left(\mathrm{P}_{\mathrm{OAin}_{\mathrm{av}}}, \mathrm{h}_{\mathrm{t}}\right) p_{\mathrm{GG}} \mathrm{h}_{\mathrm{t}} \mathrm{d} h_{t}$

It is stressed that the method here is confined to a single wavelength system. Multiple wavelengths constitute a natural further development of this work. Under such circumstances, assuming that an OA is 
not to favor particular wavelength channels systematically, it will be necessary to ensure gain flatness at least in the small-signal regime. The value of $i_{D}$ in Eq. (30) can be defined in such a way as to maintain the use of $\mathrm{Q}$ and adaptive thresholding and hence Eq. (32) in the non-adaptive thresholding process. In the adaptive case it varies with $h_{t}$ in the case of Eq. (32) it does not vary with $h_{t}$. The average BER obtained by statistically averaging the conditioned BER over the turbulence pdf is given as $[2,5,8,9,15]$

$\mathrm{BER}_{\mathrm{av}}\left(\mathrm{P}_{\mathrm{OAin}_{\mathrm{av}}}\right)=\int_{0}^{\infty} \operatorname{BER}\left(\mathrm{P}_{\mathrm{OAin}_{\mathrm{av}}}, \mathrm{h}_{\mathrm{t}}\right) p_{\mathrm{GG}} h_{t} \mathrm{~d} h_{t}$

For a non-amplified receiver system, $\mathrm{G}=1, \mathrm{~N}_{0}=0$ and then the receiver thermal noise is the dominant impairment (i.e. $\sigma_{0}=\sigma_{1}=\sigma_{\text {th }}$ ) [36]. The outage probability (OP) is thus obtained by integrating the joint pdf over the area that the instantaneous BER is greater than the BER target, and is written as;

$\mathrm{P}_{\text {OUT }}\left(\left\langle\mathrm{I}_{\mathrm{d}}\right\rangle,\left\langle\mathrm{I}_{1}\right\rangle\right)=\iint_{\mathrm{R}_{\mathrm{x}}} \mathrm{p}_{\mathrm{x}_{\mathrm{d}, \mathrm{X}_{1}}}\left(\mathrm{I}_{\mathrm{d}}, \mathrm{I}_{1}\right)\left\langle\mathrm{I}_{\mathrm{d}}\right\rangle,\left\langle\mathrm{I}_{1}\right\rangle \mathrm{dI}_{\mathrm{d}} \mathrm{dI} \mathrm{I}_{1}$

where $R_{X}$ is the region in in $\left(I_{d}, I_{1}\right)$ space where $\operatorname{BER}_{\text {inst }}\left(I_{d}, I_{1}\right)>$ BER target. Equation (34) could be simplified further as, [15]

$$
\begin{aligned}
\mathrm{P}_{\text {OUT }}\left(\left\langle\mathrm{I}_{\mathrm{d}}\right\rangle,\left\langle\mathrm{I}_{1}\right\rangle\right)= & \int_{0}^{\infty} \int_{0}^{\mathrm{I}_{\mathrm{d} T}\left(\mathrm{I}_{\mathrm{I}}\right)} \mathrm{p}_{\mathrm{X}_{\mathrm{d}}}\left(\mathrm{I}_{\mathrm{d}},\left\langle\mathrm{I}_{\mathrm{d}}\right\rangle\right) \mathrm{p}_{\mathrm{x}_{\mathrm{l}}}\left(\mathrm{I}_{1},\left\langle\mathrm{I}_{1}\right\rangle\right) \mathrm{dI}_{\mathrm{d}} \mathrm{dI}_{1} \\
& =\int_{0}^{\infty} \mathrm{p}_{\mathrm{X}_{\mathrm{l}}}\left(\mathrm{I}_{1},\left\langle\mathrm{I}_{\mathrm{l}}\right\rangle\right)\left[\int_{0}^{\mathrm{I}_{\mathrm{dT}}\left(\mathrm{I}_{\mathrm{I}}\right)} \mathrm{p}_{\mathrm{X}_{\mathrm{d}}}\left(\mathrm{I}_{\mathrm{d}},\left\langle\mathrm{I}_{\mathrm{d}}\right\rangle\right) \mathrm{dI} \mathrm{I}_{\mathrm{d}}\right] \mathrm{dI} \mathrm{I}_{1}
\end{aligned}
$$

where $\mathrm{I}_{\mathrm{dT}}\left(\mathrm{I}_{\mathrm{l}}\right)$ is the threshold instantaneous irradiance required to achieve a $B E R_{\text {inst }}$ that is equal to the BER target and is dependent on the instantaneous irradiance of the interferer. The instantaneous BER of the system is a function of the instantaneous irradiances of the signal and interferer $\left(\mathrm{I}_{\mathrm{d}}, \mathrm{I}_{1}\right),[5,8,15]$

$\mathrm{BER}_{\text {inst }}\left(\mathrm{I}_{\mathrm{d}}, \mathrm{I}_{1}\right)=\frac{1}{4} \operatorname{erfc}\left(\frac{\mathrm{Q}\left(\mathrm{I}_{\mathrm{d}}, \mathrm{I}_{\mathrm{l}}\right)}{\sqrt{2}}\right)$

$Q\left(I_{d}, I_{1}\right)=\frac{i_{1,0}\left(I_{d}, I_{1}\right)-i_{0,1}\left(I_{d}, I_{1}\right)}{\sigma_{1,0}\left(I_{d}, I_{1}\right)+\sigma_{0,1}\left(I_{d}, I_{1}\right)}$

where $\sigma_{\mathrm{d}, 1}^{2}(\mathrm{~d} \in 0,1)$ and $(1 \in 0,1)$ is the sum of the noise variances which include signal shot noise $\sigma_{\mathrm{s}-\mathrm{sh}(\mathrm{d}, \mathrm{l})}^{2}=2 \mathrm{qi}_{\mathrm{d}, \mathrm{l}}\left(\mathrm{I}_{\mathrm{d}}, \mathrm{I}_{\mathrm{l}}\right) \mathrm{B}_{\mathrm{e}}$, ASE shot noise $\sigma_{\mathrm{ASE}-\mathrm{sh}(\mathrm{d}, \mathrm{l})}^{2}=2 \mathrm{~m}_{\mathrm{t}} \mathrm{RqB}_{0} \mathrm{~B}_{\mathrm{e}}$, signal-ASE beat noise $\sigma_{\mathrm{s}-\mathrm{ASE}(\mathrm{d}, \mathrm{l})}^{2}\left(\mathrm{I}_{\mathrm{d}}, \mathrm{I}_{\mathrm{l}}\right)=4 \mathrm{RN}_{0} \mathrm{i}_{\mathrm{d}, \mathrm{l}}\left(\mathrm{I}_{\mathrm{d}}, \mathrm{I}_{1}\right) \mathrm{B}_{\mathrm{e}}$, ASE-ASE beat noise $\sigma_{\text {ASE-ASE }}^{2}=2 \mathrm{~m}_{\mathrm{t}} \mathrm{R}^{2} \mathrm{~N}_{0}^{2} \mathrm{~B}_{0} \mathrm{~B}_{\mathrm{e}}$ and thermal noise $\sigma_{\text {th }}^{2}$ and $i_{d, 1}\left(I_{d}, I_{1}\right)=i_{d}\left(I_{d}\right)+i_{l}\left(I_{1}\right)$ is the desired signal plus interferer current at the decision instant in the receiver [15]. The electrical bandwidth $\left(B_{e}\right)$ is set equal to $R_{b} / 2$ where $R_{b}$ is the data rate, $R=\eta q / h v, \eta$ is the photodetector quantum efficiency, $\mathrm{h}$ is Planck's constant, $v$ is the optical frequency, $\mathrm{q}$ is the electron charge, $\mathrm{N}_{0}$ is the single polarization ASE PSD, $G$ and NF are the optical amplifier gain and noise figure respectively, $\mathrm{B}_{0}$ is the demux channel optical noise bandwidth and $\mathrm{m}_{\mathrm{t}}$ is the number of ASE noise polarization states. The means and variances of the random variables, both are representing the integration over the slot that contains only the signal pulse, only crosstalk pulse, both signal and crosstalk pulses and no pulses (i.e. empty slot) are derived and, respectively, the general equations for the upstream transmission are derived in Eqs. (38) - (42), the equations for the downstream are recovered by replacing 
the attenuation due to atmospheric turbulence for the desired signal/interferer $\left(h_{d}, h_{i}\right)$ with $h_{z}$ written as $[2,5,8,9,29]$

$$
\begin{aligned}
& \mu_{\mathrm{X}_{\text {sig, int }}}\left(\mathrm{h}_{\mathrm{d}}, \mathrm{h}_{\mathrm{i}}\right)=\frac{\mathrm{LRqN}_{0}}{\mathrm{t}_{\mathrm{s}}}+\mathrm{Gq}\left(\operatorname{sigRP}_{\mathrm{d}}\left(\mathrm{h}_{\mathrm{d}}\right)+\operatorname{int}_{\mathrm{i}} \mathrm{P}_{\mathrm{i}}\left(\mathrm{h}_{\mathrm{i}}\right)\right) \\
& \sigma_{\mathrm{X}_{\text {sig, int }}}^{2}\left(\mathrm{~h}_{\mathrm{d}}, \mathrm{h}_{\mathrm{i}}\right)=\sigma_{\text {th }}^{2}+\left(\frac{\left(\mathrm{LRq}^{2} \mathrm{~N}_{0}\left(1+\mathrm{LRq}^{2} \mathrm{~N}_{0}\right)\right)}{\mathrm{t}_{\mathrm{s}}^{2}}\right) \\
& +\mathrm{Gq}^{2}\left[\left(\mathrm{R}+2 \mathrm{R}^{2} \mathrm{~N}_{0}\right) \frac{\operatorname{sigP}_{\mathrm{d}}\left(\mathrm{h}_{\mathrm{d}}\right)}{\mathrm{t}_{\mathrm{s}}}+\left(\mathrm{R}_{\mathrm{i}}+2 \mathrm{R}_{\mathrm{i}}^{2} \mathrm{~N}_{0, \mathrm{i}}\right) \frac{\operatorname{int}_{\mathrm{i}}\left(\mathrm{h}_{\mathrm{i}}\right)}{\mathrm{t}_{\mathrm{s}}}\right]
\end{aligned}
$$

where $\operatorname{sig} /$ int $=0$ or 1 depending on the presence of signal/crosstalk pulse in slot. $\sigma_{\mathrm{th}}^{2}$ is the DPPM thermal noise variance, $R=\frac{\eta}{h v}$, is the responsivity (in $\mathrm{A} / \mathrm{W}$ ), $\mathrm{q}$ is the electron charge, $\eta$ is PD quantum efficiency, $h$ is the Plank's constant, $v$ is the optical frequency. $L=B_{\circ} m_{t} t_{s}$ is the product of spatial and temporal modes [2], $\mathbf{B}_{\circ}$ is the demux or OBPF channel bandwidth, and $m_{t}$ is the number of ASE noise polarization states. The ASE noise PSD in a single polarization state at the photodiode is $\mathrm{N}_{\circ}$. The means and variances have been derived with modifications to account for crosstalk-ASE beat noise assuming the interferer and the desired signal experiences the same ASE noise at the amplifier output [2,29]

$$
P_{w e(l, r)}\left(h_{d}, h_{i}\right) \geq \prod_{\substack{j=1 \\ j \neq s i g} \text { slot }}^{n} P\left(X_{1, \text { int }}>X_{j} \mid h_{d}, h_{i}\right)
$$

where $X_{j}$ represents the content of the non-signal slot $X_{0, \text { int }}[29]$

$\mathrm{P}_{\text {we(1, r) }}\left(\mathrm{h}_{\mathrm{d}}, \mathrm{h}_{\mathrm{i}}\right) \leq 1-\left(1-\mathrm{P}\left(\mathrm{X}_{0,0}>\mathrm{X}_{1, \text { int }} \mid \mathrm{h}_{\mathrm{d}}, \mathrm{h}_{\mathrm{i}}\right)\right)^{\mathrm{n}-1-(1-\mathrm{r})} 1-\mathrm{p}\left(\mathrm{X}_{0,1}>\mathrm{X}_{1, \text { int }} \mid \mathrm{h}_{\mathrm{d}}, \mathrm{h}_{\mathrm{i}}\right)^{1-\mathrm{r}}$

Assuming that the random variables $X_{1, \text { int }}$ and $X_{0, \text { int }}$ are Gaussian, the expression $P\left(X_{0, \text { int }}>X_{1, \text { int }} \mid h_{d}, h_{i}\right)$ using Gaussian approximation is of the general form [29]

$\mathrm{P}\left(\mathrm{X}_{0, \text { int }}>\mathrm{X}_{1, \text { int }} \mid \mathrm{h}_{\mathrm{d}}, \mathrm{h}_{\mathrm{i}}\right)=0.5 \operatorname{erfc}\left(\frac{\mu_{\mathrm{X}_{1, \text { int }}\left(\mathrm{h}_{\mathrm{d}}, \mathrm{h}_{\mathrm{i}}\right)}-\mu_{\mathrm{X}_{0, \text { int }}\left(\mathrm{h}_{\mathrm{d}}, \mathrm{h}_{\mathrm{i}}\right)}}{\sqrt{2\left(\sigma_{\mathrm{X}_{1, \text { int }}}^{2}\left(\mathrm{~h}_{\mathrm{d}}, \mathrm{h}_{\mathrm{i}}\right)+\sigma_{\mathrm{X}_{0, \text { int }}}^{2}\left(\mathrm{~h}_{\mathrm{d}}, \mathrm{h}_{\mathrm{i}}\right)\right)}}\right)$

The BERs conditional for the upstream and downstream transmission on turbulence and crosstalk frame overlap are, respectively, written as

$$
\operatorname{BER}_{\mathrm{U}_{\mathrm{l}}}\left(\mathrm{h}_{\mathrm{d}}, \mathrm{h}_{\mathrm{i}}, \mathrm{n}_{1}\right)=\mathrm{p}_{\mathrm{f}(\mathrm{l})}\left(\mathrm{n}_{1}\right) \frac{\mathrm{n}}{2(\mathrm{n}-1)}\left(\begin{array}{r}
\mathrm{p}_{\mathrm{s}(1)}(1) \mathrm{P}_{\mathrm{we}(1,1)}\left(\mathrm{h}_{\mathrm{d}}, \mathrm{h}_{\mathrm{i}}\right) \\
+\mathrm{p}_{\mathrm{s}(1)}(0) \mathrm{P}_{\mathrm{we}(1,0)}\left(\mathrm{h}_{\mathrm{d}}, \mathrm{h}_{\mathrm{i}}\right)
\end{array}\right)
$$


$\mathrm{BER}_{\mathrm{D}_{1}}\left(h_{Z}, \mathrm{n}_{1}\right)=\mathrm{p}_{\mathrm{f}(1)}\left(\mathrm{n}_{1}\right) \frac{\mathrm{n}}{2(\mathrm{n}-1)} \times\left(\begin{array}{c}\mathrm{p}_{\mathrm{s}(1)}(1) \mathrm{P}_{\mathrm{we}(1,1)}\left(h_{Z}\right) \\ +\mathrm{p}_{\mathrm{s}(1)}(0) \mathrm{P}_{\mathrm{we}(1,0)}\left(h_{Z}\right)\end{array}\right)$

where $p_{f(l)}\left(n_{1}\right)$ is the probability of $l$ crosstalk pulses hitting the single frame. Also $p_{s(l)}(r)$ is the probability of $r$ out of $l$ crosstalk pulses hitting the single slot are calculated the same as in [29]. $P_{\text {we }(l, 1)}\left(h_{d}, h_{i}\right)$ and $P_{\text {we }(l, 0)}\left(h_{d}, h_{i}\right)$ are calculated using equation (41) for $r=1$ and 0 which represent error probability for interfere and the desired signal for different turbulent regimes in the upstream transmission. Also $P_{w e(l, 1)}\left(h_{Z}\right)$ and $P_{w e(l, 0)}\left(h_{Z}\right)$ are calculated using Eq. (41) where the interferer and the desired signal for the same turbulence path link in the downstream transmission. The overall BER in the presence of the turbulence and crosstalk for upstream and downstream calculated using equations (43), (44) respectively $[2,5,8,29]$

$\overline{\mathrm{BER}_{\mathrm{U}}}=\int_{0}^{\infty} \frac{1}{\mathrm{n}} \sum_{\mathrm{n}_{1}=0}^{\mathrm{n}-1} \sum_{\mathrm{l}=0}^{2} \mathrm{BER}_{\mathrm{U}_{1}}\left(\mathrm{~h}_{\mathrm{d}}, \mathrm{h}_{\mathrm{i}}, \mathrm{n}_{1}\right) p_{\mathrm{GG}, \mathrm{d}}\left(\mathrm{h}_{\mathrm{d}}\right) \times p_{\mathrm{GG}, \mathrm{i}}\left(\mathrm{h}_{\mathrm{i}}\right) \mathrm{dh}_{\mathrm{d}} \mathrm{dh}_{i}$

$\overline{\mathrm{BER}_{\mathrm{D}}}=\int_{0}^{\infty} \frac{1}{\mathrm{n}} \sum_{\mathrm{n}_{1}=0}^{\mathrm{n}-1} \sum_{\mathrm{l}=0}^{2} \mathrm{BER}_{\mathrm{D}_{\mathrm{l}}}\left(h_{Z}, \mathrm{n}_{1}\right) p_{\mathrm{GG}, \mathrm{d}}\left(h_{Z}\right) \mathrm{d} h_{Z}$

For fixes misalignment of signal frames and crosstalk, (45) and (46) are modified to exclude the requirements of averaging over all values for the upstream and downstream transmission of $\left(n_{1}\right)$. The BERs conditional under the assumption of independent signal and crosstalk channels for upstream and downstream transmission, the average turbulence which accentuated interchannel crosstalk BER of given fixed transmitter powers for the signal and crosstalk [15]

$\overline{\mathrm{BER}}=\int_{0}^{\infty} \int_{0}^{\infty} \mathrm{BER}\left(\mathrm{h}_{\text {sig }}, \mathrm{h}_{\text {int }}\right) p_{\mathrm{GG}, \text { sig }}\left(\mathrm{h}_{\mathrm{sig}}\right) p_{\mathrm{GG}, \text { int }}\left(\mathrm{h}_{\text {int }}\right) \mathrm{dh}_{\text {sig }} \mathrm{dh}_{\text {int }}$

where $p_{G G, \text { sig }}\left(h_{\text {sig }}\right)$ and $p_{G G, \text { int }}\left(h_{\text {int }}\right)$ are respectively, the signal and interferer GG pdfs each with different $\alpha, \beta$ and $\sigma_{R}^{2}$ as writen in [15, 29-34]. For performance calculations it is assumed to have signal mux/demux loss $L_{\text {mux }}$ and $L_{\text {demux }}(\leq 3.5 \mathrm{~dB})$ [29], Using a Gaussian approximation, the BER conditioned on $\left(\mathrm{h}_{\text {sig }}\right)$ and $\left(\mathrm{h}_{\text {int }}\right)$ for upstream transmission with single interchannel crosstalk $[2,5,8,15]$

$$
\begin{aligned}
& \operatorname{BER}\left(\mathrm{h}_{\text {sig }}, \mathrm{h}_{\text {int }}\right)=\frac{1}{4} \operatorname{ercc}\left(\frac{\mathrm{Q}\left(\mathrm{h}_{\text {sig }}, \mathrm{h}_{\text {int }}\right)}{\sqrt{2}}\right) \\
& \mathrm{Q}\left(\mathrm{h}_{\text {sig }}, \mathrm{h}_{\text {int }}\right)=\frac{\mathrm{i}_{1,0}\left(\mathrm{~h}_{\text {sig }}, \mathrm{h}_{\text {int }}\right)-\mathrm{i}_{0,1}\left(\mathrm{~h}_{\text {sig }}, \mathrm{h}_{\text {int }}\right)}{\sigma_{1,0}\left(\mathrm{~h}_{\text {sig }}, \mathrm{h}_{\text {int }}\right)+\sigma_{0,1}\left(\mathrm{~h}_{\text {sig }}, \mathrm{h}_{\text {int }}\right)}
\end{aligned}
$$




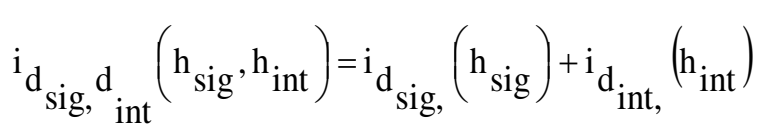

where $i_{d_{\text {sig }},{ }_{\text {int }}}\left(h_{\text {sig }}, h_{\text {int }}\right)$ is the resulting signal $\left(\mathrm{d}_{\text {sig }}=0\right.$ or 1$)$ and interferer $\left(\mathrm{d}_{\text {int }}=0\right.$ or 1$)$ current at decision circuit. where $i_{d_{\text {sig }}, d_{\text {int }}}\left(h_{\text {sig }}, h_{\text {int }}\right)$ is the resulting signal $i_{d_{\text {sig }}}\left(h_{\text {sig }}\right)+i_{d_{\text {int }}}\left(h_{\text {int }}\right)=\left(d_{\text {sig }}=0\right.$ or 1$)$ and interferer $\left(d_{i n t}=0\right.$ or 1$)$ current at the decision circuit are written as [15], $i_{d_{s i g}}\left(h_{s i g}\right)=\alpha d_{s i g} R P_{R, s i g}\left(h_{\text {sig }}\right)$ and $i_{d_{\text {int }}}\left(h_{\text {int }}\right)=$ $\alpha d_{i n t} R P_{R, \text { int }}\left(h_{\text {int }}\right)$ is the signal and interferer current for data 1 and 0 , are, respectively. $P_{R, s i g}$ and $P_{R, \text { int }}$ are respectively the instantaneous received signal and interferer average powers, respectively. $a_{o}=2 /(r+1), a_{1}=2 r /(r+1), r$ is the extinction ratio. $R=\eta q / E$ is the responsivity (in $\mathrm{A} / \mathrm{W}$ ), $\eta$ is the PD quantum efficiency, $q$ is the electron charge, $E=h f_{c}$ is the photon energy, $h$ is Planck's constant, $f_{c}$ is the optical frequency. The total OLT receiver noise variance $\sigma_{d_{s i}, d_{i t t}}^{2}$ is the summation of the signal shot noise, ASE shot nose, signal-ASE beat noise, and ASE-ASE beat noise variance, given respectively in Eqs. (51) (54), plus the thermal noise variance $\sigma_{t h}^{2}[5,8,15]$

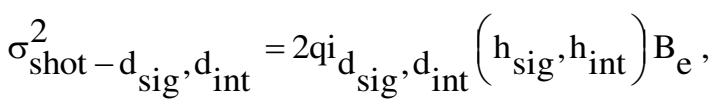

$$
\begin{aligned}
& \sigma_{\text {shot, } A S E}^{2}=2 m_{t} B_{\circ} N_{\circ} q R B_{e} \\
& \sigma_{\text {sig }-d_{\text {sig }}, d_{\text {int }}-A S E}=4 R N_{o} i_{d_{\text {sig }}}, d_{\text {int }}\left(h_{\text {sig }}, h_{\text {int }}\right) B_{e} \text {, } \\
& \sigma_{A S E-A S E}^{2}=2 m_{t} R^{2} N_{\circ}^{2} B_{\circ} B_{e} \text {. } \\
& \operatorname{BER}\left(P_{R, s i g}(1)\right)=\frac{1}{4} \operatorname{erfc}\left(\frac{2(r-1) R P_{R, s i g}(1) /(r+1)}{2 q B_{e} R P_{R, s i g}(1)+\sigma_{t h}^{2}}\right)
\end{aligned}
$$

In the second one, it has the form

$$
B E R=\frac{1}{4} \int_{0}^{\infty} \operatorname{erfc}\left(\frac{2(\mathrm{r}-1) R \cdot P /(r+1)}{2 q B_{e} R \cdot P+\sigma_{t h}^{2}}\right) p_{G G}\left(\frac{P}{P_{R, s i g}(1)}\right) d P
$$

where

$$
\begin{aligned}
& p_{G G}\left(\frac{P}{P_{R, s i g}(1)}\right)=\frac{2(\alpha \beta)^{(\alpha+\beta) / 2}}{\Gamma(\alpha) \Gamma(\beta)}\left(\frac{P}{P_{R, \text { sig }}(1)}\right)^{\frac{\alpha+\beta}{2}-1} \times \\
& \times K_{\alpha-\beta}\left(2 \sqrt{\alpha \beta \frac{P}{P_{R, s i g}(1)}}\right) .
\end{aligned}
$$

Finally, in the last case the dependence is the following [8]: 


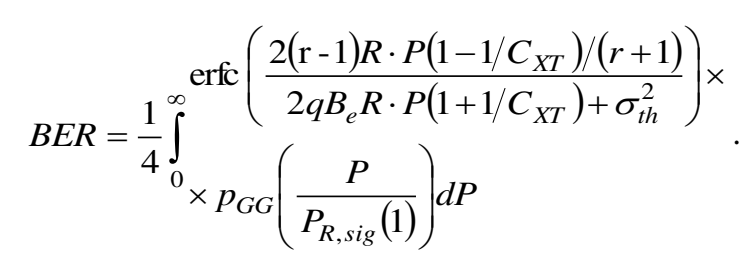

The following values of the input parameters are reported in Table 2. The major challenge consists in taking integrals in the right hand sides of the Eqs. (56) and (58) properly. To find correct values for the integral limits in these equations, one should examine the dependence that is the following as written in [15].

\section{Calculations results and discussion}

The physical parameters used in the model are listed in Table 2. $\mathrm{N}_{\mathrm{o}_{-} \mathrm{XT}}$ is fixed by $\mathrm{N}_{\mathrm{o}} / \mathrm{C}_{\mathrm{XT}}$ at the receiver with $\mathrm{C}_{\mathrm{XT}}>1$, i.e. assuming that the crosstalk and the accompanying ASE have been attenuated by the demultiplexer upon pairing to the desired signal photodetector. The same data rate is assumed for both crosstalk and signal $[5,8]$. The DPPM thermal noise variance is back-calculated using a bandwidth expansion factor such that $\sigma_{\text {th-DPPM }}^{2}=B_{\text {exp }} \sigma_{\text {th-OOK }}^{2}$ where $B_{\exp }=2^{M} / M$ is the DPPM bandwidth growing factor and $\sigma_{\mathrm{th}-\mathrm{OOK}}^{2}=7 \times 10^{-7} \mathrm{~A}$ is obtained from a model of a PIN-field effect The physical parameters used in the model are listed in Table 2. $\mathrm{N}_{\mathrm{o}}$ XT is fixed by $\mathrm{N}_{\mathrm{o}} / \mathrm{C}_{\mathrm{XT}}$ at the receiver with $\mathrm{C}_{\mathrm{XT}}>1$, i.e. assuming that the crosstalk and the accompanying ASE have been attenuated by the demultiplexer upon pairing to the desired signal photodetector. The same data rate is assumed for both crosstalk and signal [5, 8]. The DPPM thermal noise variance is back-calculated using a bandwidth expansion factor such that $\sigma_{\text {th-DPPM }}^{2}=\mathrm{B}_{\text {exp }} \sigma_{\text {th-OOK }}^{2}$ where $B_{\text {exp }}=$ $2^{\mathrm{M}} / \mathrm{M}$ is the DPPM bandwidth growing factor and $\sigma_{\mathrm{th}-\mathrm{OOK}}^{2}=7 \times 10^{-7} \mathrm{~A}$ is obtained from a model of a PIN-field effect transistor receiver with $R_{b}=2.5$ Gbps at BER of $10^{-12}$ assuming a sensitivity of $-23 \mathrm{dBm}[5,8-10,36]$.

The demux (or OBPF) channel bandwidth is $80 \mathrm{GHz}$ with $100 \mathrm{GHz}$ adjacent channel spacing, this is about the same as those seen in $[5,8,37,38]$ and will easily accommodate the slot rate of $45.7 \mathrm{GHz}$ for maximum DPPM coding level of $M=7$ analyzed [2]. Typical values for adjacent channel rejection ratio ranges from -20 $\mathrm{dB}$ to $-30 \mathrm{~dB}[5,8-10,37-39]$.

Table 2 Physical parameters used for calculations.

\begin{tabular}{|c|c|c|c|c|}
\hline Parameters & Description & Values [2] & Values [29] & Values [Proposed] \\
\hline $\mathrm{R}_{\mathrm{b}}$ & Binary data rate & $2.5 \mathrm{Gbps}$ & $2.5 \mathrm{Gbps}$ & $2.5 \mathrm{Gbps}$ \\
\hline $\mathrm{B}_{\mathrm{o}}$ & $\begin{array}{l}\text { Demux channel optical noise } \\
\text { bandwidth }\end{array}$ & $80 \mathrm{GHz}$ & $76 \mathrm{GHz}$ & $80 \mathrm{GHz}$ \\
\hline$\lambda_{\text {sig }}$ & Signal wavelength & $1550 \mathrm{~nm}$ & $1550 \mathrm{~nm}$ & $1550 \mathrm{~nm}$ \\
\hline$\eta$ & Receiver quantum efficiency & 0.75 & 0.9 & 1 \\
\hline G & Optical preamplifier gain & $30.6 \mathrm{~dB}$ or $8.8 \mathrm{~dB}$ & $27 \mathrm{~dB}$ or $8 \mathrm{~dB}$ & $30 \mathrm{~dB}$ or $8 \mathrm{~dB}$ \\
\hline NF & Optical preamplifier noise figure & $4.77 \mathrm{~dB}[2]$ & $4.77 \mathrm{~dB}[2]$ & $4.77 \mathrm{~dB}[2]$ \\
\hline $\boldsymbol{l}_{\mathrm{fso}}$ & Optical link length & $1000 \mathrm{~m}$ and $1500 \mathrm{~m}$ & $1000 \mathrm{~m}$ and $1500 \mathrm{~m}$ & $1500 \mathrm{~m}$ and $4000 \mathrm{~m}$ \\
\hline $\mathrm{m}_{\mathrm{t}}$ & ASE noise polarization states & 2 & 2 & 2 \\
\hline
\end{tabular}

Fig. 5 shows a comparison of the $\mathrm{GA}, \mathrm{CB}$, and $\mathrm{MCB}$ performance at low gain $\mathrm{G}=8 \mathrm{~dB}$ and high gain $\mathrm{G}$ $=30 \mathrm{~dB}$ with a single crosstalk source and $\mathrm{M}=2[5,9,29]$. The MCB coincides with the GA at low gain, but shifts close to the $\mathrm{CB}$ at high gain as the ASE noise reduces the significance of the thermal noise. The GA on the other hand is seen to exceed the CB and MCB (which are upper bounds) at high gain with no crosstalk and in the presence of crosstalk. Fig. 6 shows the BER curves for CB, MCB, and $\mathrm{GA}$ at low gain optical amplifier $(\mathrm{G}=8 \mathrm{~dB})$ and $\mathrm{G}=30 \mathrm{~dB}$ ). Fig. 6 (a) shows the discrepancy between the $\mathrm{K}$ and the GG distribution. Fig. 6 (b) shows the BER curves for the high-gain $(\mathrm{G}=30 \mathrm{~dB})$ case using 
the same parameters as before to characterize the atmospheric turbulence regimes. Here the $\mathrm{CB}$ and $\mathrm{MCB}$ BER curves are almost matching, while the GA differs from both CB and MCB, even more as the turbulence strength increases $[9,10]$. Consideration of both Fig. 6 (a) and (b) indicates that the MCB with GG distribution is probably the most sensible approach for modeling optically pre-amplified FSO receiver in all atmospheric turbulence regimes. This is because the MCB gives a tighter bound than the CB especially when the contribution of the thermal noise is relatively high and because the GG distribution is reasonable over a whole range of turbulence conditions.
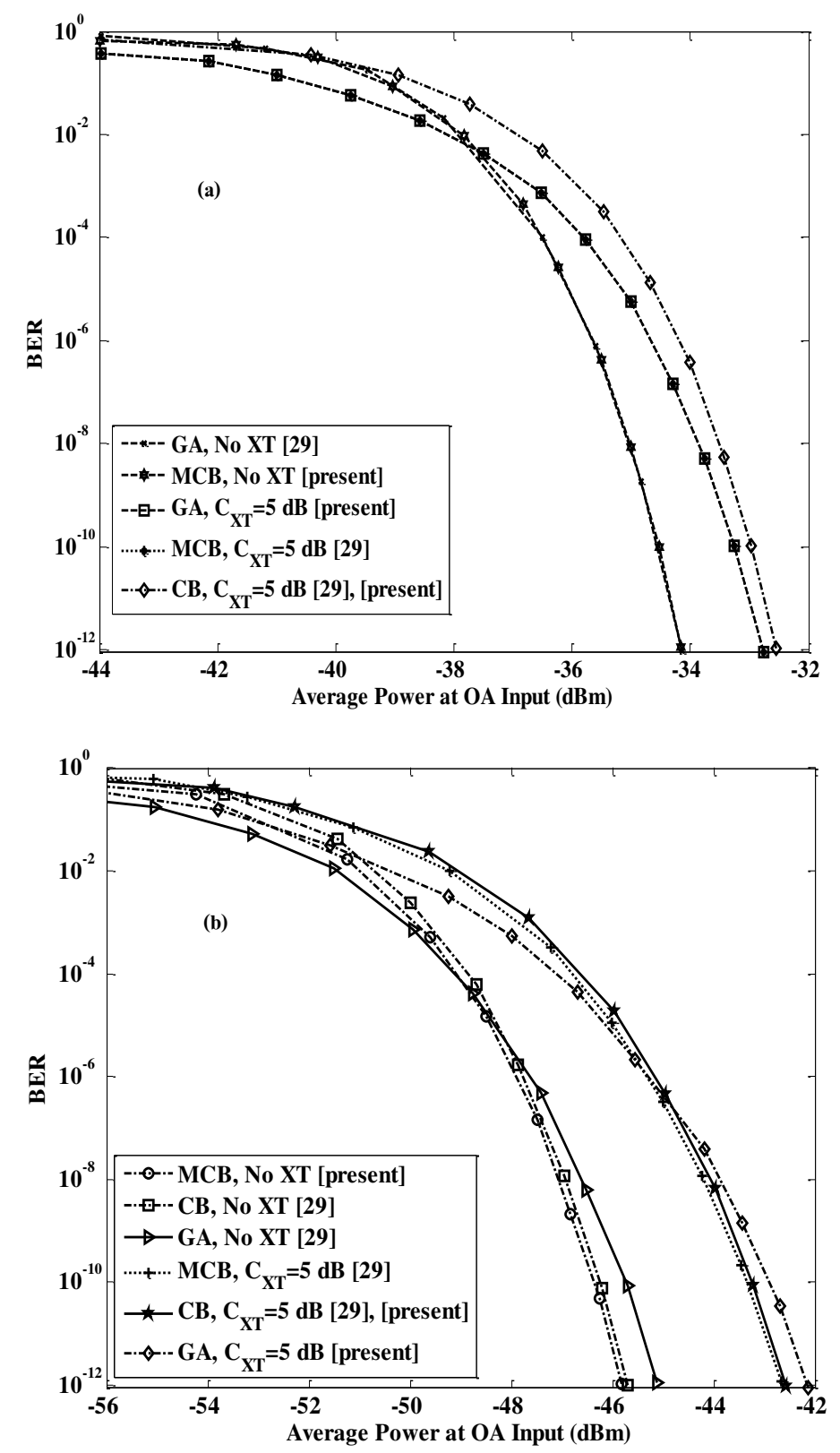

Figure 5 BER against average power at $\mathrm{OA}$ input $(\mathrm{dBm})$ using $\mathrm{M}=2$, for FA single crosstalk with $\mathrm{C}_{\mathrm{XT}}=5 \mathrm{~dB}$, (a) $\mathrm{G}$ $=8 \mathrm{~dB}$ and $(\mathbf{b}) \mathrm{G}=30 \mathrm{~dB}$. 

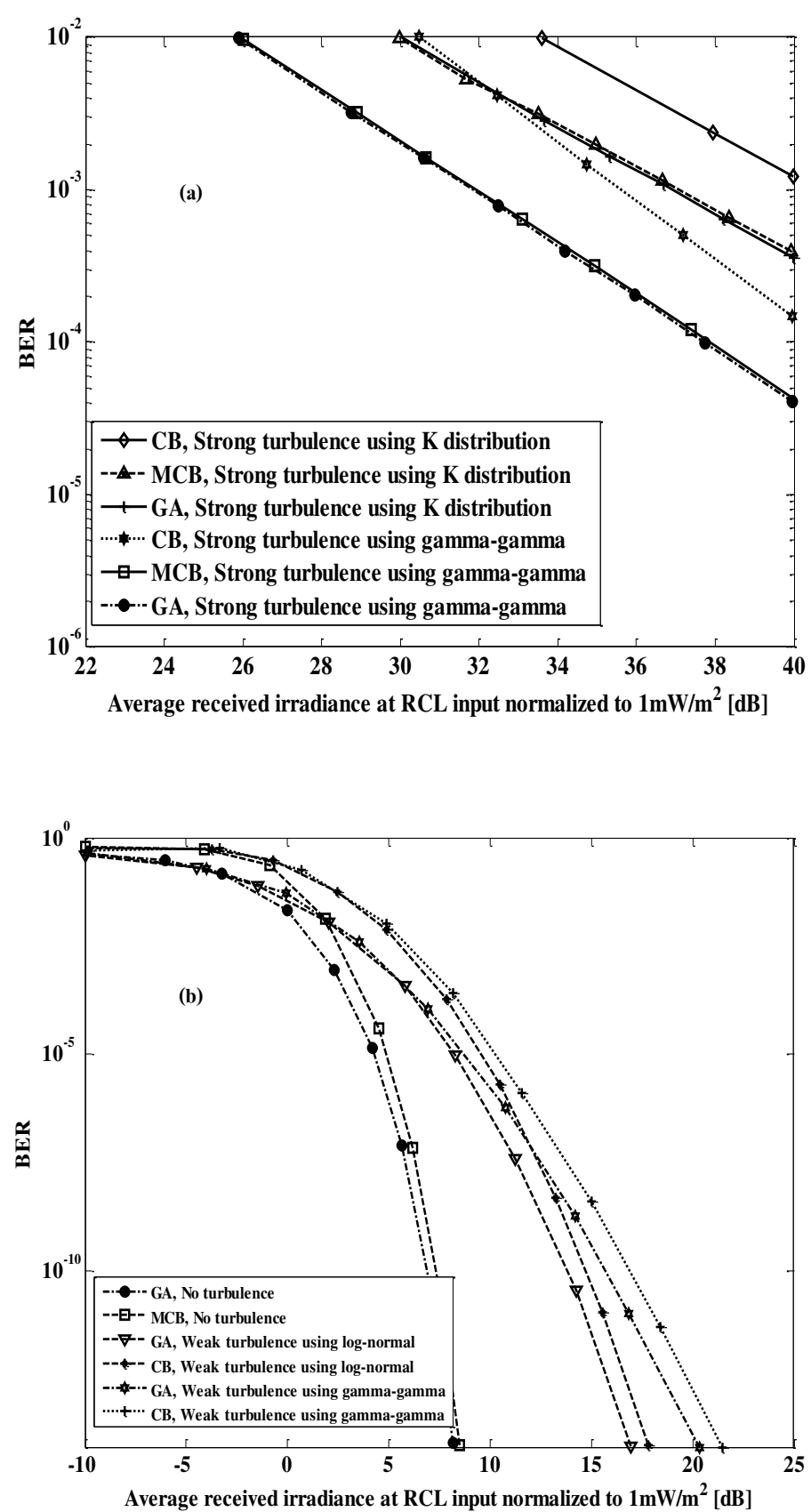

Figure 6 BER against normalized average received irradiance at RCL input $[\mathrm{dB}]$ using (a) $\mathbf{G}=8 \mathrm{~dB}$ ), and $D_{R X}=4 \mathrm{~mm}$ for strong turbulence using GG and $\mathrm{K}$ distributions, (b) $\mathrm{G}=30 \mathrm{~dB}$ and $\mathrm{D}_{\mathrm{RX}}=4$ $\mathrm{mm}$ for no turbulence (NT), and weak turbulence using log-normal and gamma-gamma (GG) distribution.

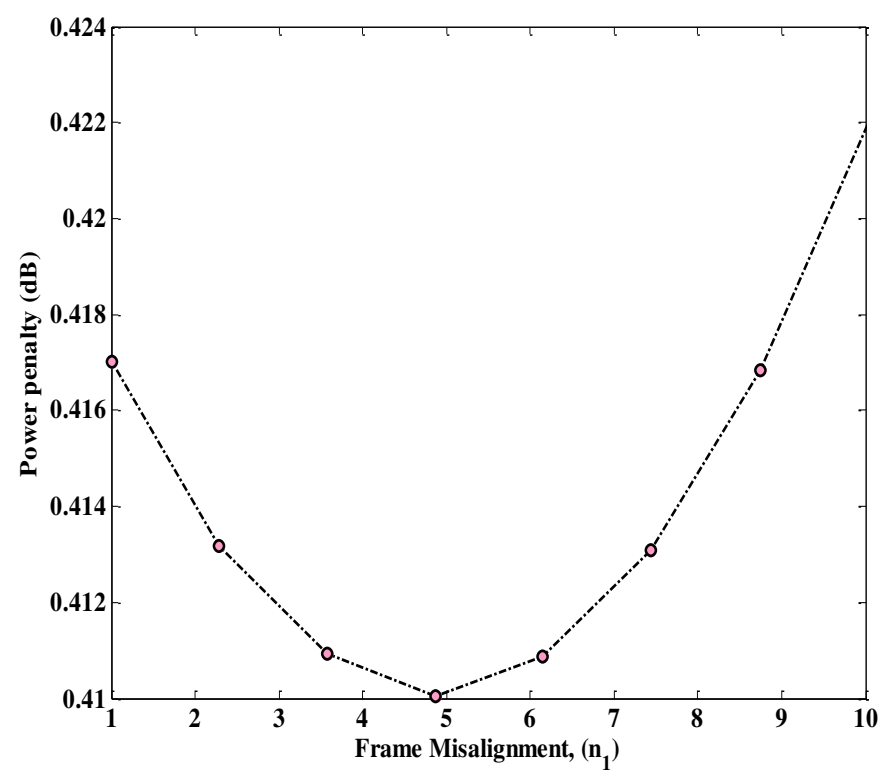

Figure 7 Power penalty as a function of fixed misalignment using MCB (single crosstalk) for $\mathrm{M}=3$ and $\mathrm{C}_{\mathrm{XT}}=10 \mathrm{~dB}$ at $\mathrm{BER}=10^{-9}$ for Frame misalignment in OSA case.

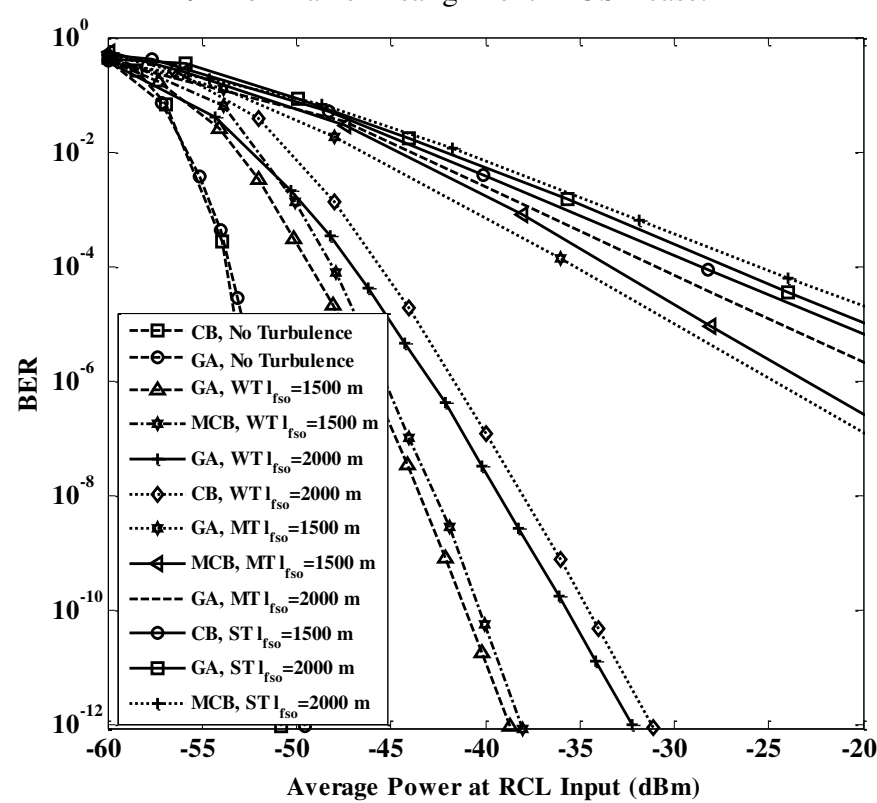

Figure 8 BER vs. average power at receiver collecting lens (RCL) input (dBm) using $\mathrm{M}=5, l_{\mathrm{fso}}=1500 \mathrm{~m}$ and $2000 \mathrm{~m}$, $\mathrm{G}=30 \mathrm{~dB}, \mathrm{D}_{\mathrm{RX}}=1 \mathrm{~mm}$ for no turbulence (NT) and $\mathrm{WT}$, MT and ST, all with averaging aperture. 
To further understand the single crosstalk system, consider Fig. 7 which shows the result of the power penalty as a function of fixed misalignment case. Each point in Fig. 7 presents the power penalty for the different fixed slot alignments (subcases) that are averaged to obtain the overall power penalty for the OSA case [5]. The penalty at $n_{1}=8$ corresponds to the penalty for FA. The best performance for the fixed slot alignments is attained at $n_{1}=4$, this is because the probability of no crosstalk impairing the signal frame $p_{f(0)}\left(n_{1}\right)$ is highest for such misalignment [5]. In Fig. 8, the BER curves are presented for two typical FSO optical link lengths i.e. $l_{\mathrm{fso}}=1500 \mathrm{~m}$ and $l_{\mathrm{fso}}=2000 \mathrm{~m}$, using $\mathrm{G}=30 \mathrm{~dB}, \mathrm{D}_{\mathrm{RX}}=1 \mathrm{~mm}$ and $\mathrm{M}=5$ for NT with WT, MT, and ST regimes $[9,10]$, respectively. Here it can be seen that the effect of turbulence becomes more severe for the longer optical link (recall that $\mathrm{C}_{\mathrm{n}}^{2}$ is fixed, so the Rytov variance is where the length change impacts), for example, at target BER, the receiver sensitivity degrades by about $5 \mathrm{~dB}$ (WT), $12 \mathrm{~dB}$ (MT), and $8 \mathrm{~dB}$ (ST) as optical link length increase from $1500 \mathrm{~m}$ to $2000 \mathrm{~m}$. Specifically, the effect of the optical link length gradually becomes less significant as the turbulence strength approaches very strong regimes $[5,9,10,40]$ for NT condition, receiver sensitivities of about $-50.25 \mathrm{dBm}(\sim 27.2$ photons/bit) (GA), $-51.4 \mathrm{dBm}(\sim 21.9$ photons/bit) (CB) and $-51.5 \mathrm{dBm}$ (21.4 photons/ bit, MCB) can be achieved, which implies an improvement when compared to the fundamental limit (38 photons/bit) of non-turbulent optically pre-amplified OOK-NRZ as stated in [40] as shown in Fig. 8. The result of DPPM power penalty analyses for crosstalk $M=2$ is compared with the power penalty for OOK in Fig. 9 for target BER of $10^{-9}$. DPPM predicts a reasonable penalty which is less than the OOK penalty for multiple crosstalks, even at low coding levels. The DPPM improvement in the power penalty becomes better as the number of crosstalk sources increases and as the coding level increases from $M=1$ to 2 . The FA is compared with OSA and simulation for $M=2$ [5, 40]. Although the FA seems to overestimate the power penalty, the approximation gets better for $M=2$. Also, it is computationally quicker than the other approaches and provides an upper bound for the system. In the absence of turbulence and at a data rate of $2.5 \mathrm{Gbps}$ on the $1550 \mathrm{~nm}$ wavelength, DPPM systems with a coding level of 2 provide about $2 \mathrm{~dB}$ improvement in average power over an equivalent OOK NRZ system while maintaining minimum bandwidth expansion as seen in Fig. 9 [5, 8, 9]. As a numerical method, it is necessary to judge and review the validity of the BERs versus average power at the optical amplifier input. Fig. 10 shows a comparison of the GA, CB, and MCB performance at high gain $\mathrm{G}=27 \mathrm{~dB}[5$, 29 ] and $\mathrm{G}=30 \mathrm{~dB}$ [present] with a single crosstalk source and $\mathrm{M}=2$. The MCB coincides with the GA at low gain, but shifts close to the CB at high gain as the ASE noise reduces the significance of the thermal noise. The GA on the other hand is seen to exceed the $\mathrm{CB}$ and $\mathrm{MCB}$ (which are upper bounds) at high gain with no crosstalk and in the presence of crosstalk. The margin with which the GA exceeds the MCB and CB widens as the coding level and the noise equivalent bandwidth $\mathrm{B}_{\mathrm{e}}$ of the DPPM receiver increases. This erratic behavior of the GA is well reported for both OOK and DPPM systems [2, 8, 9, 24]. In Fig. 11, the receiver sensitivity for each DPPM coding level $(M=1-6)$ is presented for NT with WT, and ST, respectively, using GA, CB, and MCB, $\mathrm{G}=30.6 \mathrm{~dB}, l_{\mathrm{fso}}=1500 \mathrm{~m}, \mathrm{D}_{\mathrm{RX}}=1 \mathrm{~mm}, 20 \mathrm{~mm}$, and $50 \mathrm{~mm}$, at target BER of $10^{-9}$ that presented in [2]. At $\mathrm{M}=5, \mathrm{G}=30.6 \mathrm{~dB}$ and $\mathrm{R}_{\mathrm{b}}=2.5 \mathrm{~Gb} / \mathrm{s}$, for $\mathrm{NT}$ condition, receiver sensitivities of about $-50.53 \mathrm{dBm}$ ( 27.4 photons/bit) (GA), $-51.49 \mathrm{dBm}$ ( 22 photons/bit) $(\mathrm{CB})$, and $-51.59 \mathrm{dBm}(\sim 21.5$ photons/bit) (MCB) can be achieved, which implies an improvement when compared to the fundamental limit (38 photons/bit) of non-turbulent optically preamplified OOK-NRZ as stated in $[9,40]$ as achieved in paper [2]. While the receiver sensitivity for each DPPM coding level $(M=1-6)$ is presented for NT with WT, and ST, respectively, using GA, CB, and MCB, $G=30 \mathrm{~dB}, l_{\mathrm{fso}}=1500 \mathrm{~m}, \mathrm{D}_{\mathrm{RX}}=1 \mathrm{~mm}, 20 \mathrm{~mm}$, and $50 \mathrm{~mm}$, at target BER of $10^{-9}$ [present]. Numerical results show for NT condition, receiver sensitivities of about $-50.25 \mathrm{dBm}$ ( $\sim 27.2$ photons/bit) (GA), $-51.49 \mathrm{dBm}$ ( $\sim 22$ photons/bit) $(\mathrm{CB})$, and $-51.56 \mathrm{dBm}(\sim 21.4$ photons/bit) (MCB) can be achieved [present], which implies an improvement when compared to the fundamental limit (38 photons/bit) of non-turbulent optically preamplified OOK-NRZ as stated in [40]. To further reinforce this point, in Fig. 12, we show a plot of the required mean irradiance to achieve instantaneous BER performance target of $10^{-6}$ and $10^{-3}$ with fixed outage probability values of either $10^{-6}$ or $10^{-3}$ and the required mean irradiance to achieve average BER targets of $10^{-6}$ and $10^{-3}$ for a WDM-FSO system. From the result shown in Fig. 11, it is seen that with $\mathrm{L}_{\mathrm{demux}, \mathrm{XT}}=35 \mathrm{~dB}$ and $\mathrm{C}_{\mathrm{n}}^{2}=1 \times 10^{-13} \mathrm{~m}^{-2 / 3}$, the required mean irradiance to achieve a target instantaneous BER of $10^{-3}$ with an outage probability target of $10^{-6}$ is 
greater than the required mean irradiance to achieve a target instantaneous BER of $10^{-6}$ with an outage probability target of $10^{-3}$ for all FSO link length considered $[5,8]$. This shows that more transmitter power is required to improve OP for a given instantaneous BER target than to improve the instantaneous BER for a given OP target. From the result shown in Fig. 12 it is seen that with $\mathrm{L}_{\mathrm{demux}, \mathrm{XT}}=35 \mathrm{~dB}$ a and $C_{n}^{2}=1 \times 10^{-13} \mathrm{~m}^{-2 / 3}$, the required mean irradiance to achieve a target instantaneous BER of $10^{-3}$ with OP target of $10^{-6}$ is greater than the required mean irradiance to achieve a target instantaneous BER of $10^{-6}$ with OP target of $10^{-3}$ for all FSO link length considered [5, 8]. This shows that more transmitter power is required to improve OP for a given instantaneous BER target than to improve the instantaneous BER for a given outage probability target. For example, at $2000 \mathrm{~m}$ in Fig. 12, an extra $2.66\left(\mathrm{dBm} / \mathrm{cm}^{2}\right)$ is required to improve the instantaneous BER from $10^{-3}$ to $10^{-6}$ at a fixed OP of $10^{-3}$, while it takes an additional $14.23 \mathrm{dBm} / \mathrm{cm}^{2}$ to improve the OP from $10^{-3}$ to $10^{-6}$ at fixed instantaneous BER of $10^{-3}[5$, 8]. Figure 13, shows the required optical power $(\mathrm{dBm})$ for the upstream as a function of the refractive index structure constant $\left(\mathrm{C}_{\mathrm{n}}^{2} \mathrm{~m}^{-2 / 3}\right)$ and interferer demux channel rejection $\mathrm{L}_{\mathrm{demux}, \mathrm{XT}}(\mathrm{dB})$ at $l_{\mathrm{fso}}=2000 \mathrm{~m}$. The result shows that for target BERs of $10^{-9}, 10^{-6}$, and $10^{-3}$, to be met at all turbulence regimes, the system requires demultiplexer with an adjacent channel rejection greater or equal to $46 \mathrm{~dB}, 33 \mathrm{~dB}$, and $17 \mathrm{~dB}$, respectively. However, to meet a BER of $10^{-9}$ would require high power (above $20 \mathrm{~dB}$ ) [2, 8]. With forward error correction (FEC) implemented in most recent practical systems, operation at BER of $10^{-3}$ is becoming feasible and demultiplexers with $18 \mathrm{~dB}$ rejection are readily available [5, 8]. Fig. 14 shows the power penalty (dB) for the upstream as a function of the refractive index structure constant $\left(\mathrm{C}_{\mathrm{n}}^{2} \mathrm{~m}^{-2 / 3}\right)$ at $\mathrm{C}_{\mathrm{n}}^{2}=1 \mathrm{e}-17 \mathrm{~m}^{-2 / 3}$ and interferer demux channel rejection $\mathrm{L}_{\mathrm{demux}, \mathrm{XT}}(\mathrm{dB})$ at $l_{\mathrm{fso}}=250 \mathrm{~m}$. The result shows that the power penalty for the DPPM system tends to be lower than that of the OOK system. As shown in Fig. 14, an interferer that is closer to the remote node $(\mathrm{RN})$ causes more crosstalk to other users farther away, even at low $\left(\mathrm{C}_{\mathrm{n}}^{2} \mathrm{~m}^{-2 / 3}\right)$ value. Thus, in the absence of power control, user positioning should be considered as an important design parameter. Next, Fig. 15 illustrates the BER of the proposed system using (4-pulse position modulation (PPM) versus $\mathrm{P}_{\mathrm{s}}$, for the downstream transmission with various turbulence strengths $[5,8]$. Within the total distance of $4 \mathrm{~km}$, the BER performance constantly deteriorates when the turbulence becomes stronger (i.e., higher $\mathrm{C}_{\mathrm{n}}^{2}$ ). With only one relay $(\mathrm{N})$, the required $\mathrm{P}_{\mathrm{s}}$ to attain BER of $10^{-9}$ are $10.5 \mathrm{dBm}, 7.5 \mathrm{dBm}$, and $4.5 \mathrm{dBm}$ corresponding to $\mathrm{C}_{\mathrm{n}}^{2}$ of $10^{-14} \mathrm{~m}^{-2 / 3}, 7.5 \times 10^{-15} \mathrm{~m}^{-2 / 3}$, and $5 \times 10^{-15} \mathrm{~m}^{-2 / 3}$. With two relays, the BER performance is significantly improved compared to the case when relay $(\mathrm{N}=1)$, the performance improvements when $N=2$ are $8 \mathrm{~dB}, 7 \mathrm{~dB}$, and $6 \mathrm{~dB}$ for $\mathrm{C}_{\mathrm{n}}^{2}$ of $10^{-14} \mathrm{~m}^{-2 / 3}, 7.5 \times 10^{-15} \mathrm{~m}^{-2 / 3}$, and $5 \times 10^{-15} \mathrm{~m}^{-2 / 3}$, respectively as shown in Fig. 15 [8]. 

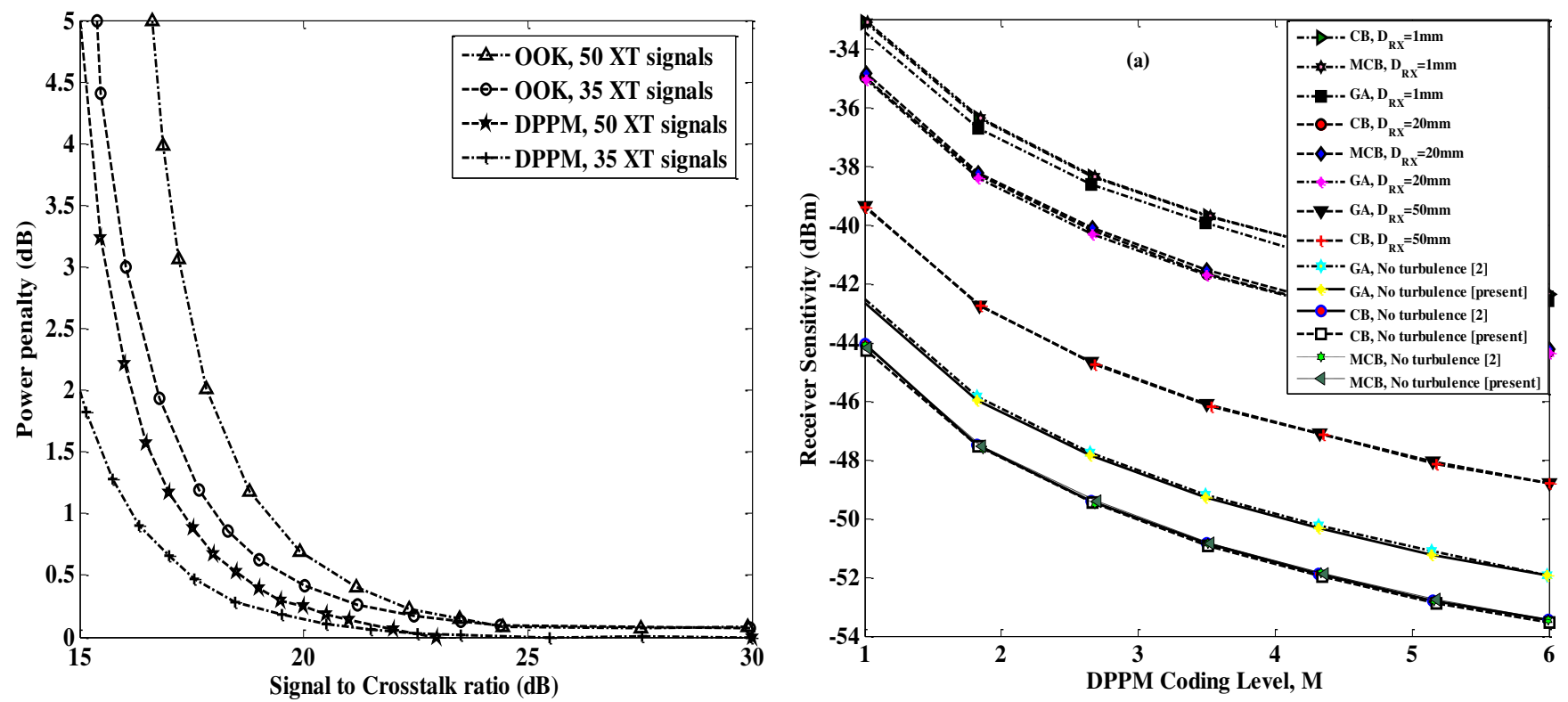

Figure 9 Power penalty against signal-to-crosstalk ratio for OOK and DPPM (multiple crosstalks OSA and simulation) at BER $=10^{-9}$ and OOK comparison with DPPM at M $=2$.

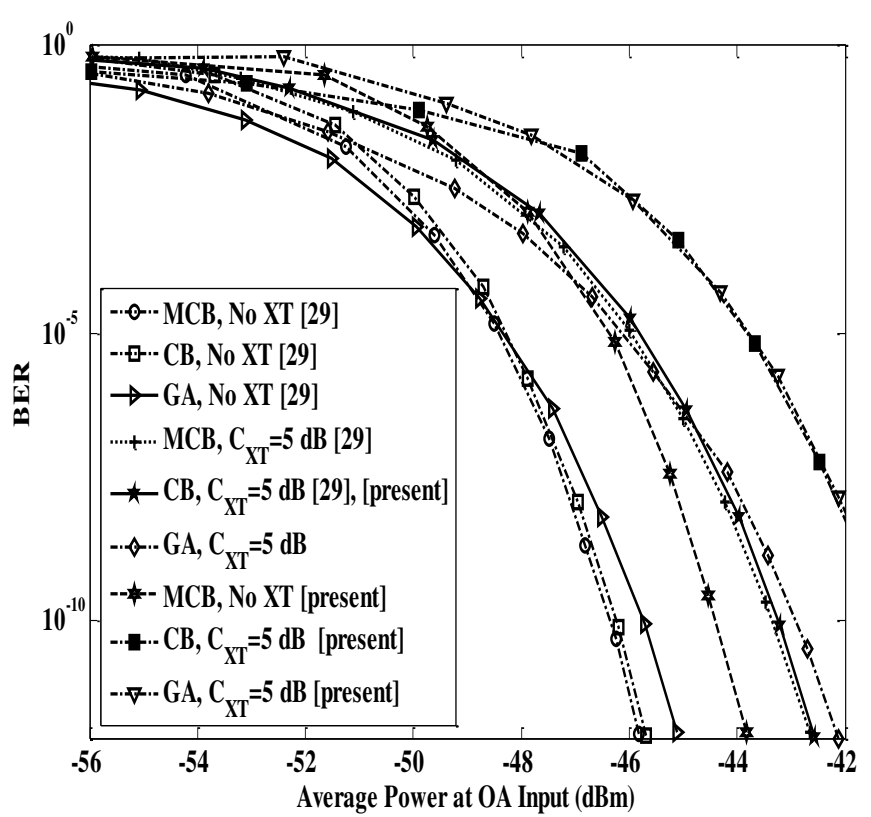

Figure 10 BER against average power at $\mathrm{OA}$ input $(\mathrm{dBm})$ using $M=2$, for FA single crosstalk with $C_{X T}=5 \mathrm{~dB}, G=$ $27 \mathrm{~dB}$ [29] and $\mathrm{G}=30 \mathrm{~dB}$ [present].

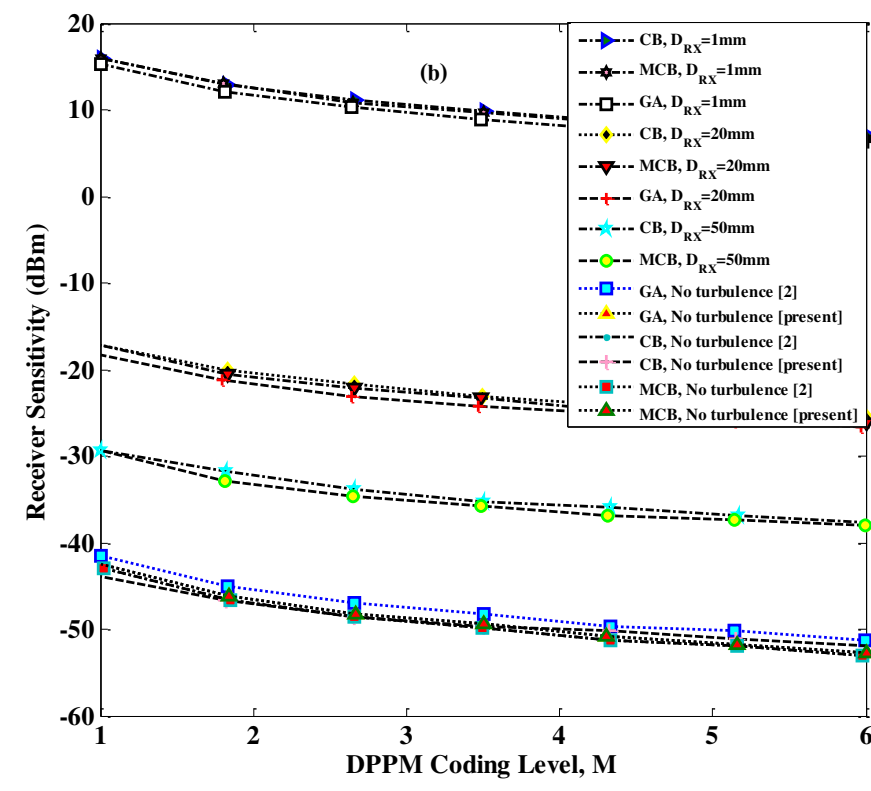

Figure 11 Receiver sensitivity for each DPPM coding level $(\mathrm{M}=1-6)$ is presented for NT with (a) WT and (b) ST [2], [present]. 


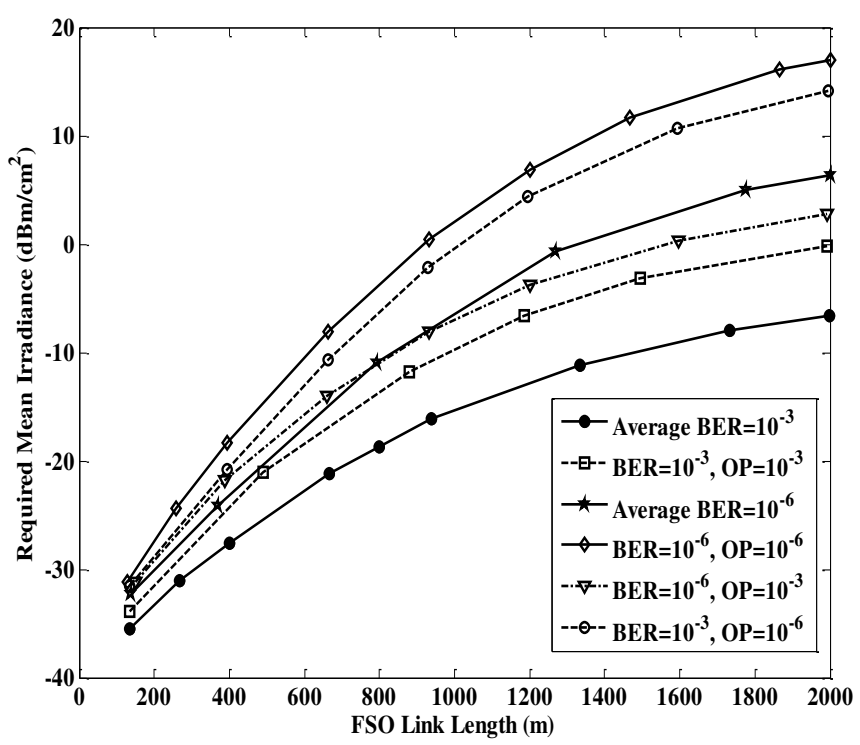

Figure 12 Required mean irradiance as a function of the FSO link length for downstream transmission to achieve instantaneous BER targets with fixed OP values and average BER targets at $\mathrm{L}_{\text {demux, } \mathrm{XT}}=35 \mathrm{~dB}$ and $\mathrm{C}_{\mathrm{n}}^{2}=$ $1 \times 10^{-13} \mathrm{~m}^{-2 / 3}$.

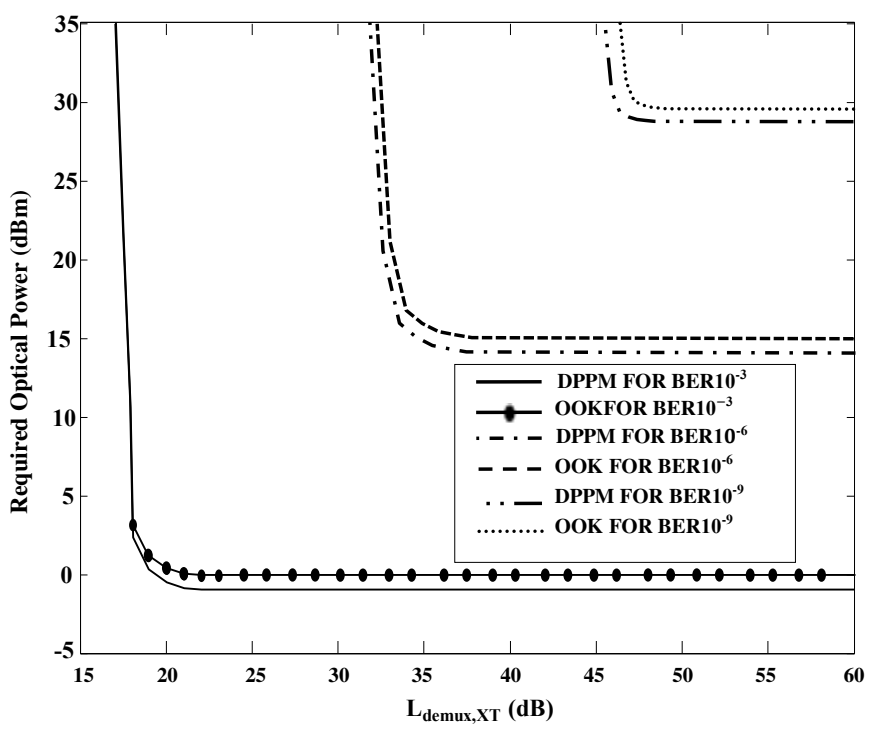

Figure 13 Required optical power $(\mathrm{dBm})$ for the upstream as a function of the refractive index structure constant $\left(\mathrm{C}_{\mathrm{n}}^{2} \mathrm{~m}^{-2 / 3}\right)$ and interferer demux channel rejection $\mathrm{L}_{\mathrm{demux}, \mathrm{XT}}(\mathrm{dB})$ at $l_{\mathrm{fso}}=2000 \mathrm{~m}$. 


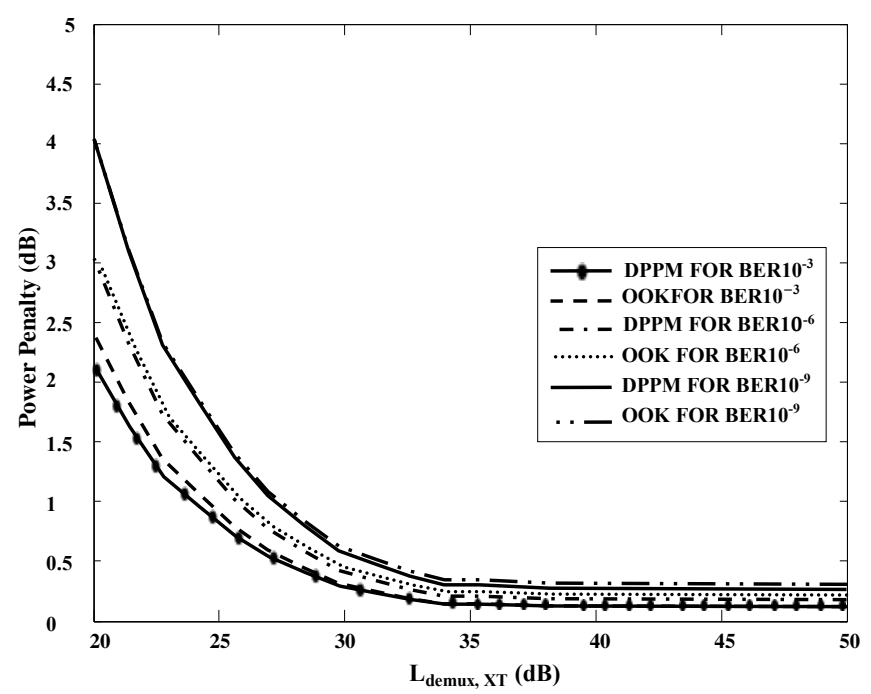

Figure 14 Power penalty $(d B)$ for the upstream as a function of the refractive index structure constant $\left(C_{n}^{2} \mathrm{~m}^{-2 / 3}\right)$ at $\mathrm{C}_{\mathrm{n}}^{2}=1 \mathrm{e}-17 \mathrm{~m}^{-2 / 3}$ and interferer demux channel rejection $\mathrm{L}_{\mathrm{demux}, \mathrm{XT}}(\mathrm{dB})$ at $l_{\mathrm{fso}}=250 \mathrm{~m}$.

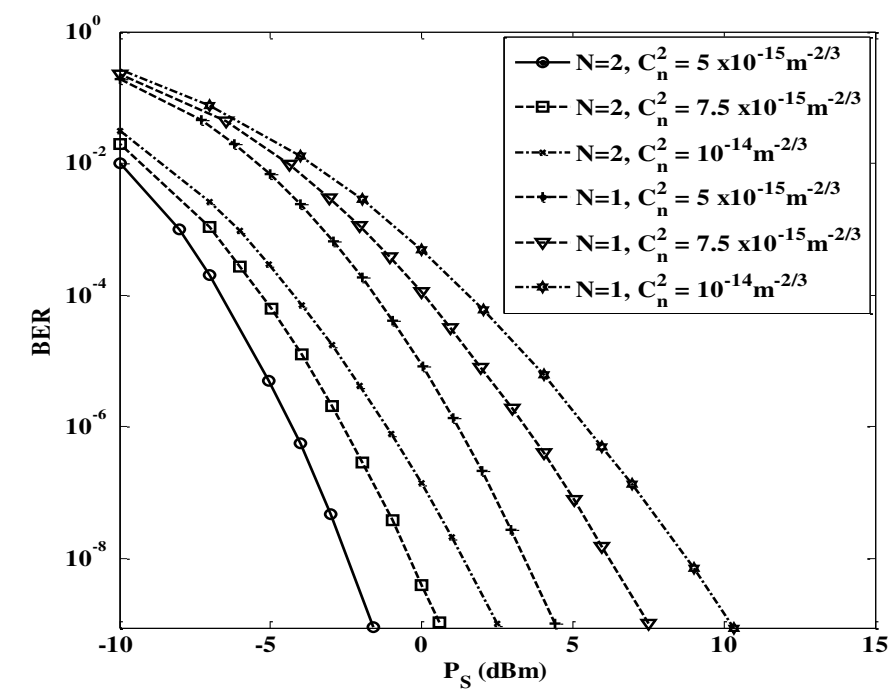

Figure 15 Downstream transmission: $\mathrm{BER}$ versus the average transmitted power per information bit $\mathrm{P}_{\mathrm{s}}$, with 4-PPM, $R_{b}=1 \mathrm{Gbps}, \mathrm{L}_{\mathrm{demux}, \mathrm{XT}}=-30 \mathrm{~dB}$, and $l_{\mathrm{fso}}=4 \mathrm{~km}$, for different turbulence strengths $\mathrm{C}_{\mathrm{n}}^{2} \mathrm{~m}^{-2 / 3}$. 


\section{Conclusions and future work}

BER modeling for optically pre-amplified M-ary DPPM FSO process taking over atmospheric turbulence is investigated utilizing MGF-based approaches such as CB and MCB. Analyses of crosstalk for optically preamplified WDM DPPM systems are given for the GA, CB, and MCB. The FA case is found to somewhat show the worst power penalty. However, the efficiency penalty is justified by a significant reduction in calculation complexity. The approach using the OSA hypothesis calls a sensible penalty compared to the state with the FA hypothesis and hence presents a better depiction of a possible system. Furthermore, the MCB is introduced as the surest approach of evaluation as it does a higher upper bound than the $\mathrm{CB}$ and is further sensitive to the optical amplification, indeed still the GA is computationally quicker. The DPPM coding level $\mathrm{M}=2$ is a reasonable option for WDM DPPM free space and wireless systems because of its sensitivity improvement for a small bandwidth expansion over OOK, and when crosstalk is performing this present significantly supported to by a reduced power penalty relative to OOK. The presence of turbulence-accentuated crosstalk for the upstream transmission which somewhat reduces the relative distances between the RN and both the interferer and the desired user for a limited target BER and demultiplexer adjacent rejection ratio was established in the proceeds. BER modeling for optically pre-amplified of M-ary DPPM in the WDM-FSO system operating over atmospheric turbulence is investigated using MGF-based techniques such as CB and MCB.

\section{Compliance with ethical standards}

Conflict of interest: The authors declare that there is no conflict of interest regarding the manuscript. The authors are responsible for the content and writing of this article. The authors declare that they have no known competing financial interests or personal relationships that could have appeared to influence the work reported in this paper.

\section{CRediT author statement}

Ebrahim E. Elsayed made substantial contributions to the design, analysis, characterization, conceptualization, methodology, software, data curation, writing-original draft, formal analysis, writing, visualization, investigation, and validation. Bedir B. Yousif participated in the conception and critical revision of the article for important intellectual content, supervision, project administration, data curation, and writing-review $\backslash \&$ editing.

No funding for this work.

\section{Author contributions}

Ebrahim E. Elsayed made substantial contributions to the design, analysis, characterization, conceptualization, methodology, software, data curation, writing-original draft, formal analysis, writing, visualization, investigation, and validation. Bedir B. Yousif participated in the conception and critical revision of the article for important intellectual content, supervision, project administration, data curation, and writing-review $\backslash \&$ editing. 


\section{References}

[1] Phillips, A.J., Cryan, R.A., Senior, J.M.: 'An optically preamplified intersatellite PPM receiver employing maximum likelihood detection', IEEE Photonics Technol. Lett., 8, (5), pp. 691-693, 1996.

[2] Aladeloba, A.O., Phillips, A.J., Woolfson, M.S.: 'Performance evaluation of optically preamplified digital pulse position modulation turbulent free-space optical communication systems', IET Optoelectron., 6, (1), pp. 66-74, 2012.

[3] Ohtsuki, T.: 'Performance analysis of indoor infrared wireless systems using PPM CDMA', Electron. Commun. Jpn. I, Commun.), 85, (1), pp. 1-10, 2002.

[4] Leeson, M.S.: 'Pulse position modulation for spectrum-sliced transmission', IEEE Photonics Technol. Lett., 16, (4), pp. 1191-1193, 2004.

[5] eprints.nottingham.ac.uk.

[6] Garrett, I.: 'Pulse-position modulation for transmission over optical fibers with direct or heterodyne detection', IEEE Trans. Commun., 31, (4), pp. 518-527, 1983.

[7] Phillips, A.J., Cryan, R.A., Senior, J.M.: 'Optically preamplified pulse-position modulation for fibre-optic communication systems', IEE Proc., Optoelectron., 143, (2), pp. 153-159, 1996.

[8] Ebrahim E. Elsayed, Bedir B. Yousif, and Mahmoud M. Alzalabani, "Performance enhancement of the power penalty in DWDM FSO communication using DPPM and OOK modulation", Optical and Quantum Electronics, vol. 50 (7), pp. 282, (26 June 2018).

[9] Ebrahim E. Elsayed and Bedir B. Yousif, "Performance enhancement of M-ary pulse-position modulation for a wavelength division multiplexing free-space optical systems impaired by interchannel crosstalk, pointing error, and ASE noise", Optics Communications, vol. 475, pp. 126219, (15 November 2020).

[10] Ebrahim E. Elsayed and Bedir B. Yousif, "Performance enhancement of the average spectral efficiency using an aperture averaging and spatial-coherence diversity based on the modifiedPPM modulation for MISO FSO links", Optics Communications, vol. 463, pp. 125463, (15 May 2020).

[11] Andrade, M. D., Kramer, G., Wosinska, L., Jiajia, C., Sallent, S., Mukherjee, B.:'Evaluating strategies for evolution of passive optical networks'. IEEE Commun. Mag., 49, (7), pp. 176-184, 2011.

[12] Kramer G., Pesavento G.: 'Ethernet passive optical network (EPON): building a next-generation optical access network'. IEEE Commun. Mag., 40, (2), pp. 66-73, 2002.

[13] Bongtae, K., Byoung-Whi, K.: 'WDM-PON development and deployment as a present optical access solution'. Conf. on Optical Fiber Commun. - incudes post deadline papers, pp. 1-3, 2009.

[14] Nirmalathas W. Ke, Nirmalathas A. Lim, Skafidas C. E.: ' $4 \times 12.5 \mathrm{~Gb} / \mathrm{s}$ WDM Optical Wireless Communication System for Indoor Applications'. J. Lightw. Technol., 29, (13), pp. 1988-1996, 2011.

[15] Aladeloba, A. O., Woolfson, M. S., Phillips, A. J.: 'WDM FSO Network with TurbulenceAccentuated Interchannel Crosstalk'. J. Opt. Commun. Netw., 5, (6), pp. 641-651, 2013.

[16] Gee-Kung, C., Chowdhury, A., Zhensheng, J., Hung-Chang, C., Ming-Fang, H., Jianjun, Y., Ellinas G.: 'Key Technologies of WDM-PON for Future Converged Optical Broadband Access Networks [Invited]'. IEEE/OSA J. of Optical Commun. and Networking, 1, (4), pp. C35-C50, 2009.

[17] Mukherjee, B.: 'WDM optical communication networks: progress and challenges', IEEE J. Sel. Areas Commun., 18, (10), pp. 1810-1824, 2000.

[18] Ciaramella, E., Arimoto, Y., Contestabile, G., et al.: '1.28 Terabit/s $(32 \times 40 \mathrm{Gbit} / \mathrm{s}) \mathrm{WDM}$ transmission system for free space optical communications', IEEE J. Sel. Areas Commun., 27, (9), pp. 1639-1645, 2009.

[19] Forbes, M., Gourlay, J., Desmulliez, M. 'Optically interconnected electronic chips: a tutorial and review of the technology', J. Electron. Commun. Eng., 13, (5), pp. 221-232, 2001. 
[20] Ansari, N., Zhang, J.: 'Media access control and resource allocation for next generation passive optical networks' (Springer, 2013).

[21] Zuo, T.J., Phillips, A.J.: 'Performance of burst-mode receivers for optical digital pulse position modulation in passive optical network application', IET Optoelectron., 3, (3), pp. 123-130, 2009.

[22] Olsson, N.A.: 'Lightwave systems with optical amplifiers', J. Lightwave Technol., 7, (7), pp. 1071-1082, 1989.

[23] Yamamoto, Y.: 'Noise and error rate performance of semiconductor laser amplifiers in PCM-IM optical transmission systems', IEEE J. Quantum Electron., 16, (10), pp. 1073-1081, 1980.

[24] Ribeiro, L.F.B., Da Rocha, J.R.F., Pinto, J.L.: 'Performance evaluation of EDFA preamplified receivers taking into account intersymbol interference', J. Lightwave Technol., 13, (2), pp. 225232, 1995.

[25] O'Reilly, J., Da Rocha, J. R. F.: 'Improved error probability evaluation methods for direct detection optical communication systems', IEEE Trans. Inf. Theory, 33, (6), pp. 839-848, 1987.

[26] Al-Orainy A. A. and O'Reilly J. J.: 'Error probability bounds and approximations for the influence of crosstalk on wavelength division multiplexed systems'. IEE Proc. J. Optoelectron., 137, (6), pp. 379-384, 1990.

[27] Personick, S. D.: 'Applications for quantum amplifiers in simple digital optical communication systems'. Bell Sys. Tech. J., 52, (1), pp. 117-133, 1973.

[28] Zuo Ma, R., Sujecki T. J., and Phillips A. J.: 'Improved performance evaluation for DC-coupled burst mode reception in the presence of amplified spontaneous emission noise and interchannel crosstalk'. IET Optoelectron., 4, (3), pp. 121-132, 2010.

[29] Mbah, A.M., Walker, J.G., Phillips, A.J.: 'Performance evaluation of digital pulse position modulation for wavelength division multiplexing FSO systems impaired by interchannel crosstalk', IET Optoelectron., 8, (6), pp. 245-255, 2014.

[30] Andrews L. C., Phillips R. L., and Hopen C. Y., 'Laser Beam Scintillation with Applications'. Bellingham, Washington: SPIE Press, 2001.

[31] Phuc V. TRINH, Ngoc T. DANG, Truong C. THANG, Anh T. PHAM, 'Performance of alloptical amplify-and-forward WDM/FSO relaying systems over atmospheric dispersive turbulence channels', IEICE Trans. Commun. E99-B (6) (2016).

[32] Majumdar A. K., "Free-space laser communication performance in the atmospheric channel," J. Opt. Fiber Commun.Rep., vol. 2, pp. 345-396, 2005.

[33] Khalighi, M., Schwartz, N., Aitamer, N., Bourennane, S.: 'Fading reduction by aperture averaging and spatial diversity in optical wireless systems', J. Opt. Commun. Netw., 1, (6), pp. 580-593, 2009.

[34] Al-Habash M. A., Andrews L. C., and Phillips R. L., "Mathematical model for the irradiance probability density function of a laser beam propagating through turbulent media," Opt. Eng., vol. 40, pp. 1554-1562, Aug. 2001.

[35] Popoola, W.O., Ghassemlooy, Z.: 'BPSK Subcarrier intensity modulated free-space optical communications in atmospheric turbulence', J. Lightwave Technol., 27, (8), pp. 967-973, 2009.

[36] Ramaswami, R., Sivarajan, K. N., Sasaki, G. H. Optical Networks: A Practical Perspective. 3rd ed. Boston: Morgan Kaufmann Publishers; 2010.

[37] Maru, K., Mizumoto, T., Uetsuka, H.: 'Demonstration of Flat-Passband Multi/Demultiplexer Using Multi-Input Arrayed Waveguide Grating Combined With Cascaded Mach-Zehnder Interferometers'. J. Lightw. Technol., 25, (8), pp.2187-2197, 2007.

[38] Hirano, A., Miyamoto, Y., Kuwahara, S.: 'Performances of CSRZ-DPSK and RZDPSK in 43Gbit/s/ch DWDM G.652 single-mode-fiber transmission'. Optical Fiber Commun. Conf., 2003, pp. 454-456, 2003.

[39] Yu, C. X., Neilson, D. T.: 'Diffraction-grating-based (de)multiplexer using image plane transformations'. IEEE J. Selected Topics in Quantum Electronics, 2002, 8, (6), pp. 1194-1201, 2002 . 
[40] Henry P. S., Error-rate performance of optical amplifiers, Optical Fiber Communication Conference, Houston, Texas, vol. 5, Feb. 1989.

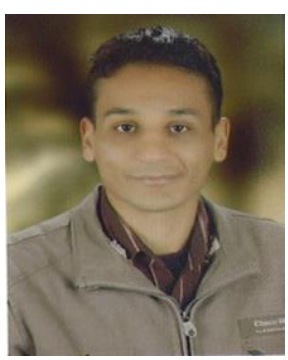

Ebrahim Eldesoky Elsayed received his B.Sc., degree in Electronics and Communications Engineering from the Misr Higher Institute for Engineering and Technology at Mansoura, Ministry of Higher Education, Mansoura, Egypt, in May 2012. In June 2015, he obtained his Diploma in Engineering Applications of Lasers (EAL), the National Institute of Laser Enhanced Sciences - (NILES), Cairo University, Egypt. In May 2017, he received a Postgraduate Diploma (PgDip.) degree - (higher Diploma) from the Department of EAL, the NILES - Cairo University, at Giza, Egypt. He received his M.Sc., degree in Electrical Communications Engineering from the Department of Electronics and Communications Engineering, Faculty of Engineering Mansoura University, Al-Mansoura, Egypt, in Nov 2018. He has several publications in optical communications, optical wireless communications, free-space optical communication systems, WDM optical networks, and communication channels modeling. He has published over 6 peer-reviewed papers in reputed international journals like IEEE Access, Springer, and Elsevier. His current research interests are in optical wireless communications, free-space optics, optoelectronics, optical devices, and MIMO systems. Also, he serves as a peer reviewer in IEEE Access, IEEE Communications Letters, IEEE Wireless Communications, Telecommunication Systems, and Wireless Personal Communications.

Google Scholar: https://scholar.google.com/citations?hl=ar\&user=e1717yIAAAAJ

Research Gate: https://www.researchgate.net/profile/Ebrahim_Elsayed3

Linkedin: https://www.linkedin.com/in/ebrahim-eldesoky-elsayed-125287126/

ORCID: $\quad$ https://orcid.org/0000-0002-7208-2194 
CV:

https://drive.google.com/file/d/1G2m9UXbETphT2OsIWXy_KR1E1Fo5XVEv/view?u $\mathrm{sp}=$ sharing

Publons: https://publons.com/researcher/3015075/ebrahim-eldesoky-elsayed/

\section{Institutions}

- A Researcher - Electronics and Communications Engineering, Faculty of Engineering, Mansoura University, Egypt from 2013 until the present.

- A Researcher - Engineering Applications of Lasers, the National Institute of Laser Enhanced Sciences (NILES), Cairo University, Giza, Egypt from 2015 until 2017.

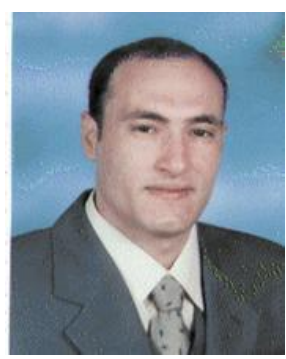

Bedir Bedir Yousif received his B.Sc., degree in Electronics Engineering from the Faculty of Electronic Engineering, Menoufia University, Egypt, in 1999, and the M.Sc., and Ph.D.'s degrees from the Department of Electronics and Communications Engineering, Faculty of Engineering-Mansoura University, Mansoura, Egypt, in 2006 and 2013, respectively. $\mathrm{He}$ is currently an Associate Professor at the Electrical Engineering Department with Electronics and Communications Engineering Branch, Faculty of Engineering-Kafrelsheikh University, Kafrelsheikh, Egypt. Prof. Bedir has several publications in the modeling of plasmonic devices, optical communications, optoelectronic devices, free-space optics networks, nano-electronics, and antennas. He has authored/co-authored more than 40 peer-reviewed papers in reputed international journals like IEEE Access, Springer, Elsevier, and AIP Advances including 30+ journal articles, on these topics. He has over 23 years of teaching and research experience. His current research topics and teaching include optical wireless communications and freespace optics, the modeling of electromagnetic devices, nano-electronics, photonic systems, and optical communications. Prof. Bedir serves as a peer reviewer in IEEE Access and National Academy Science Letters. 


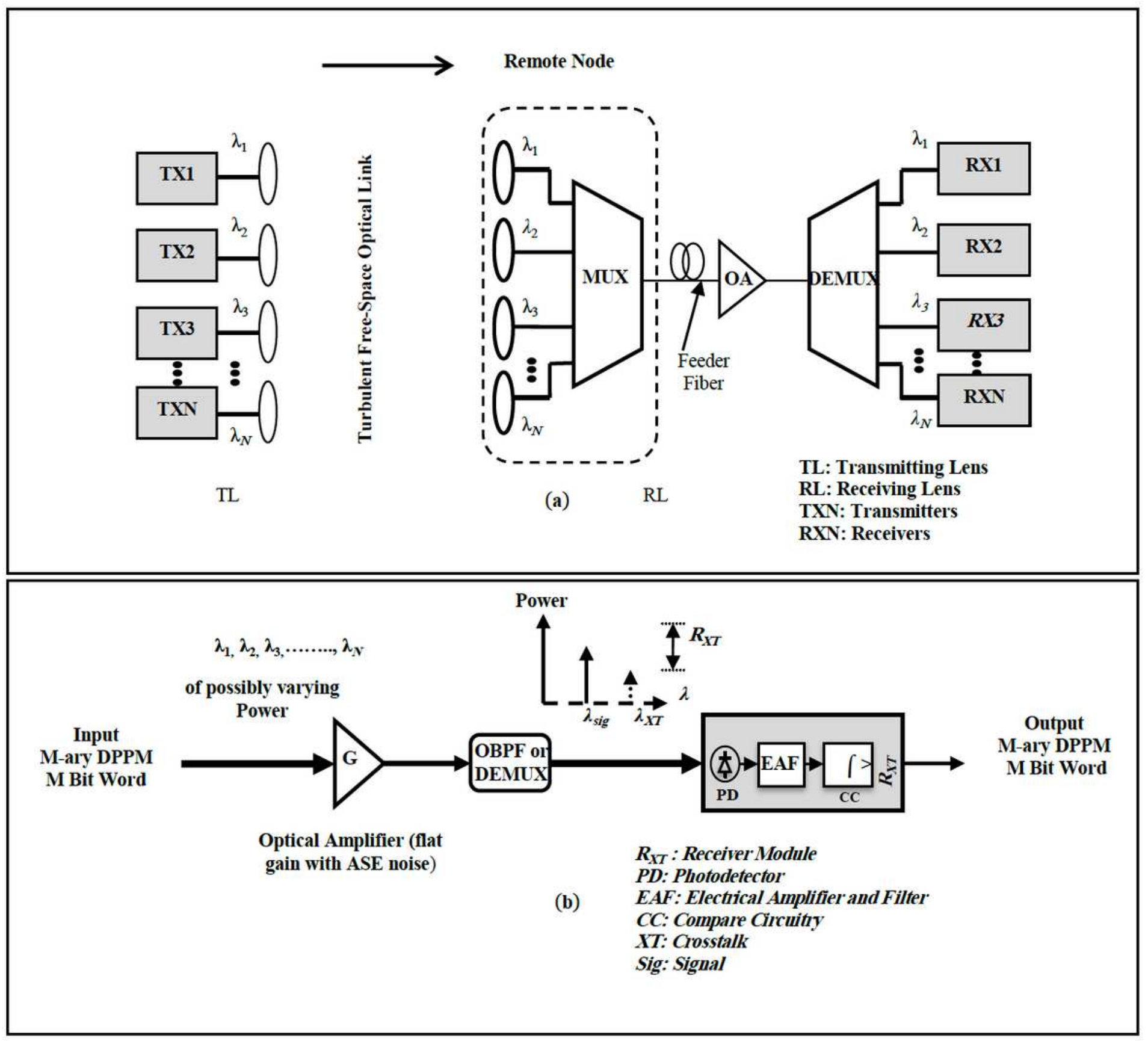

Figure 1

Structure for optically pre-amplified WDM/M-ary DPPM scheme of PON-HFFSO system: (a) Specific system architecture for crosstalk evaluation and (b) Generic receiver system. We reproduced it from our previous publication in [9]. 


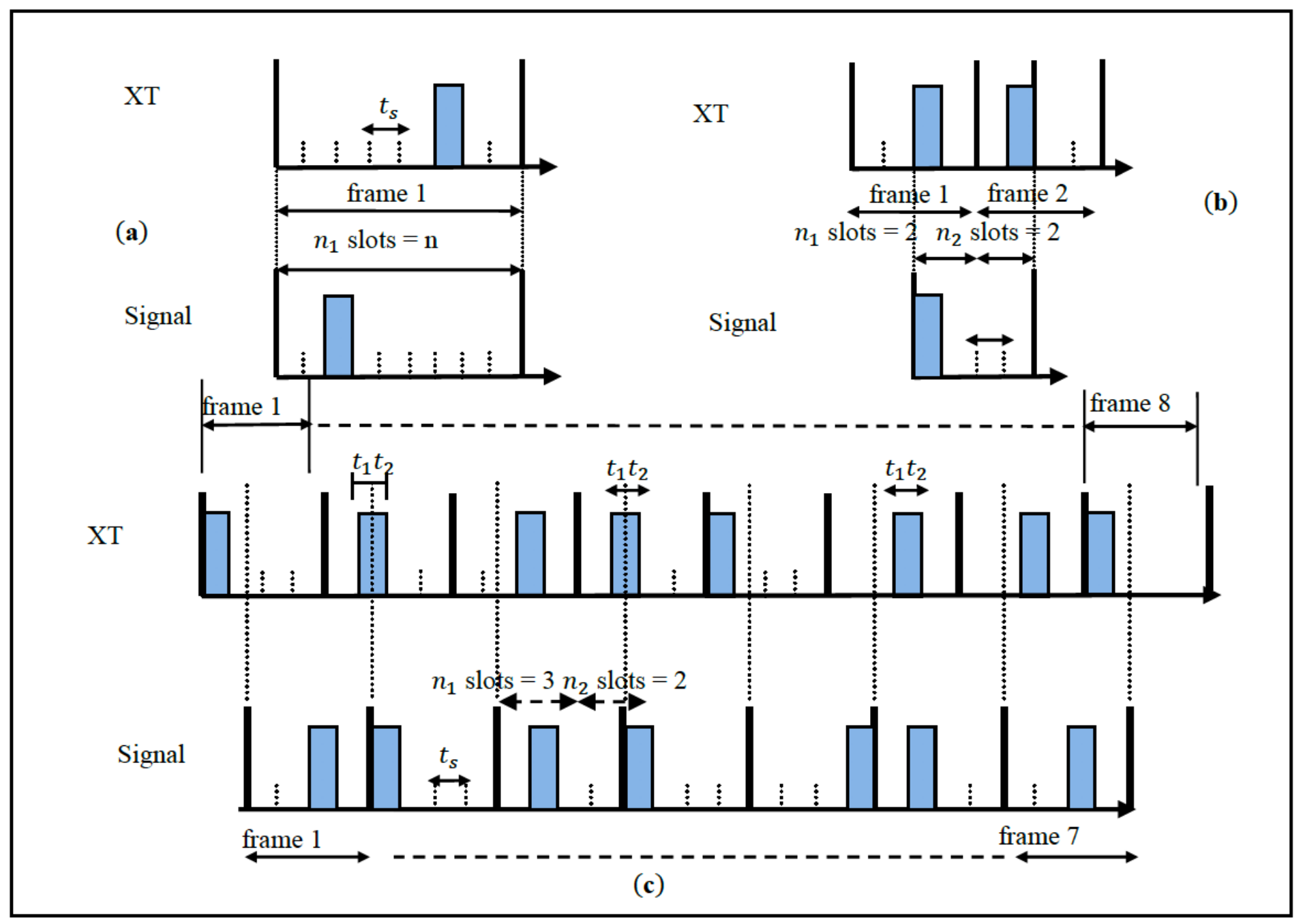

Figure 2

Illustration of crosstalk in WDM-M-ary DPPM receiver: (a) Frames aligned (FA) for M = 3, (b) Only slots aligned (OSA) for $M=2$ and (c) Slots (and frames) misaligned (SMis) for $M=2$. 


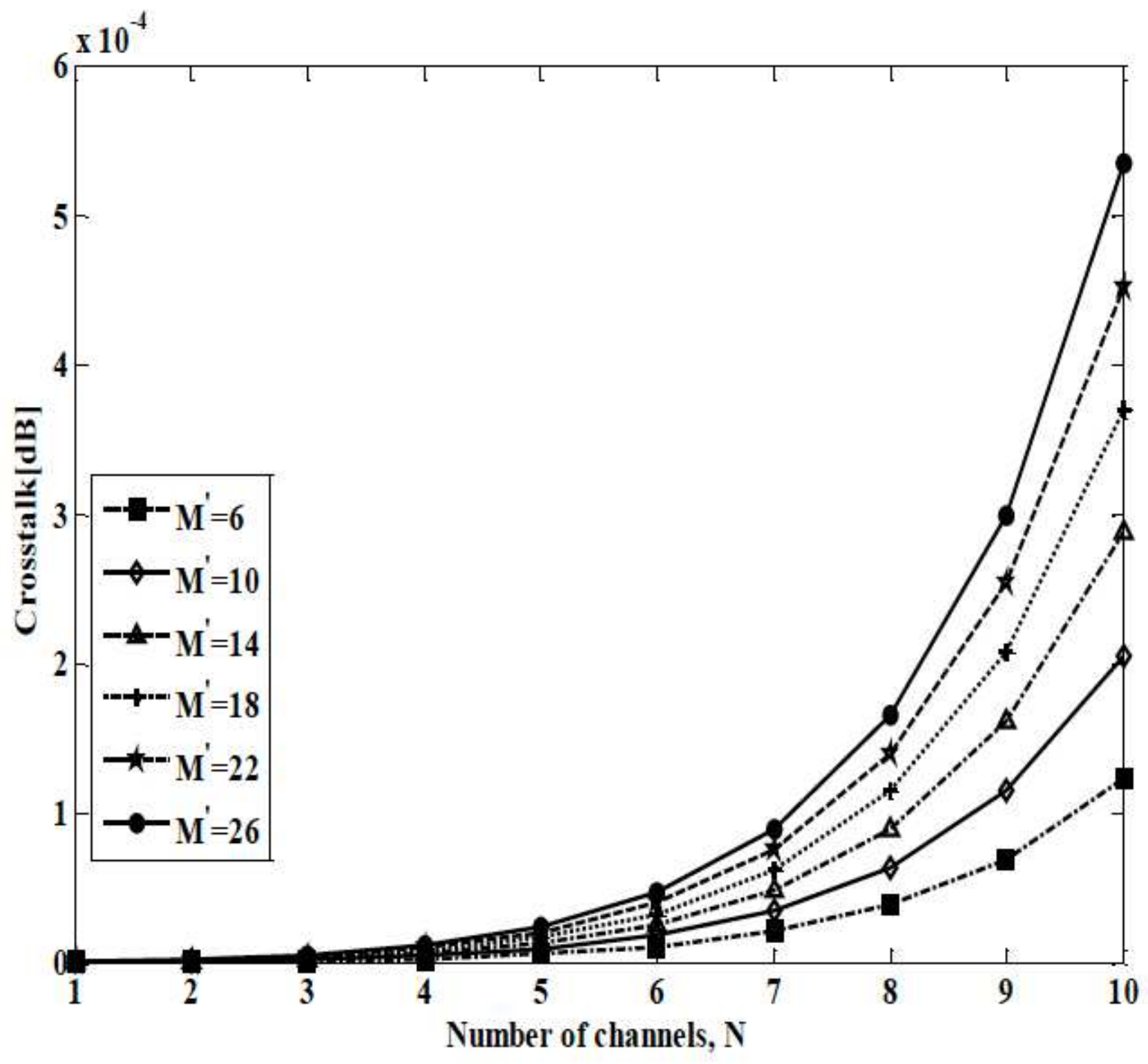

Figure 3

Crosstalk vs. the number of channels. 


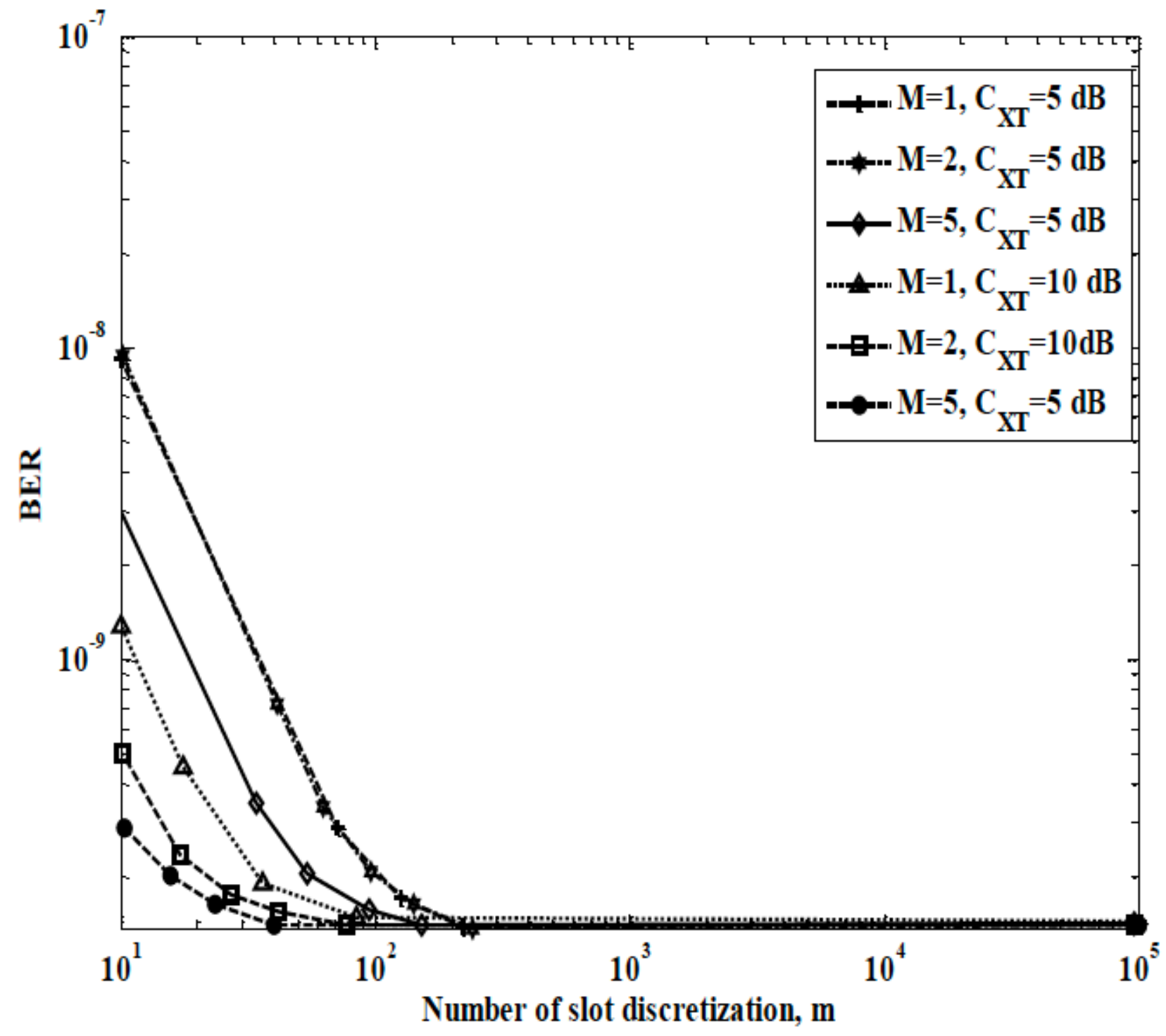

Figure 4

BER as a function of the number of slot discretization $(m)$ for SMis using MCB, $G=30 \mathrm{~dB}$, for single crosstalk with a received power corresponding to BER $-10^{\wedge}-10$. ( $\mathrm{m}$ is a dimensionless modeling artifact. 

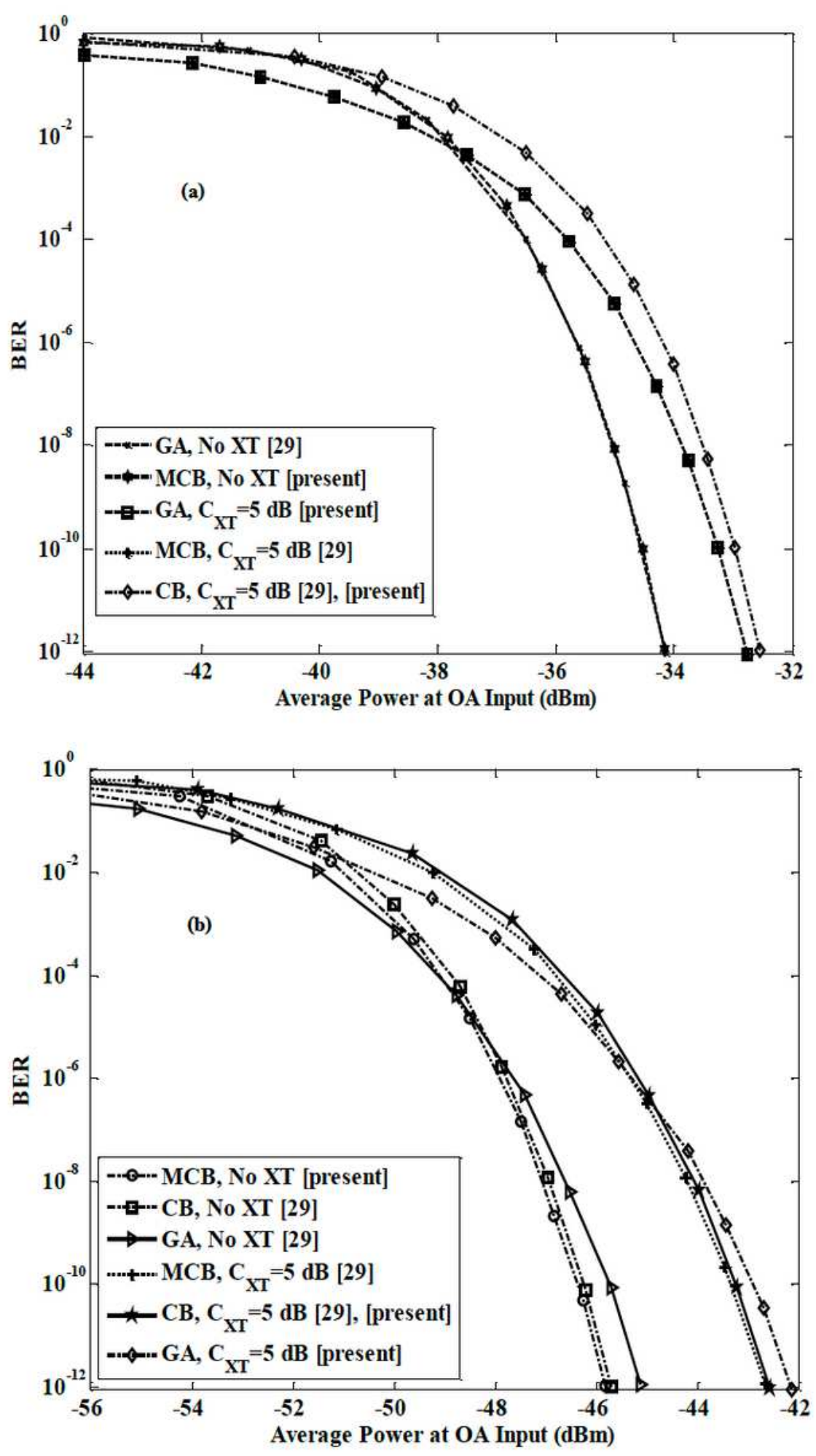

\section{Figure 5}

BER against average power at $O A$ input $(\mathrm{dBm})$ using $M=2$, for $F A$ single crosstalk with $C \_X T=5 \mathrm{~dB},(\mathrm{a}) \mathrm{G}$ $=8 \mathrm{~dB}$ and $(\mathrm{b}) \mathrm{G}=30 \mathrm{~dB}$. 

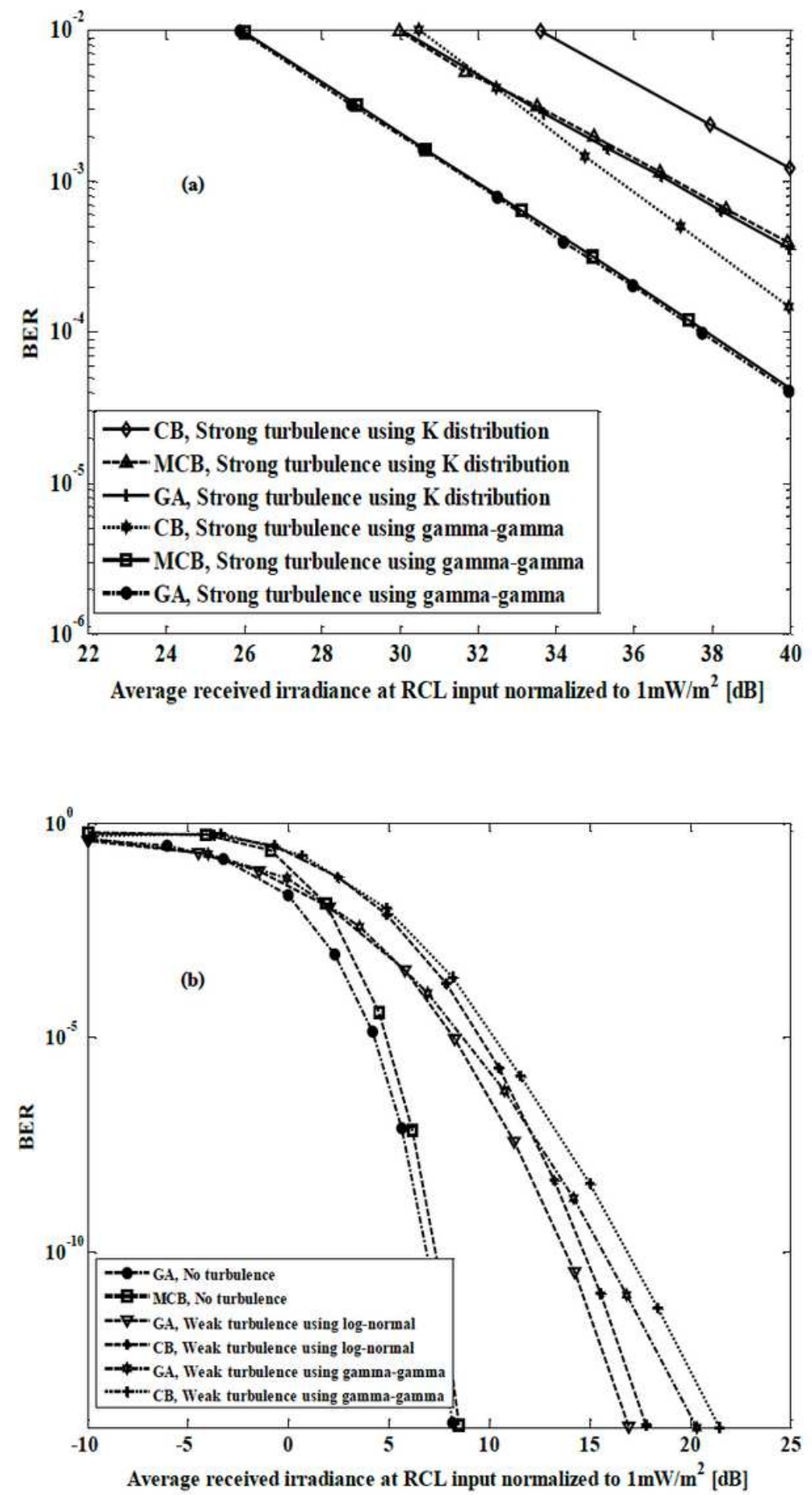

\section{Figure 6}

BER against normalized average received irradiance at $R C L$ input $(d B)$ using (a) $G=8 d B$ ), and D_RX $=4$ $\mathrm{mm}$ for strong turbulence using $\mathrm{GG}$ and $\mathrm{K}$ distributions, (b) $\mathrm{G}=30 \mathrm{~dB}$ and $\mathrm{D}_{-} \mathrm{RX}=4 \mathrm{~mm}$ for no turbulence (NT), and weak turbulence using log-normal and gamma-gamma (GG) distribution. 


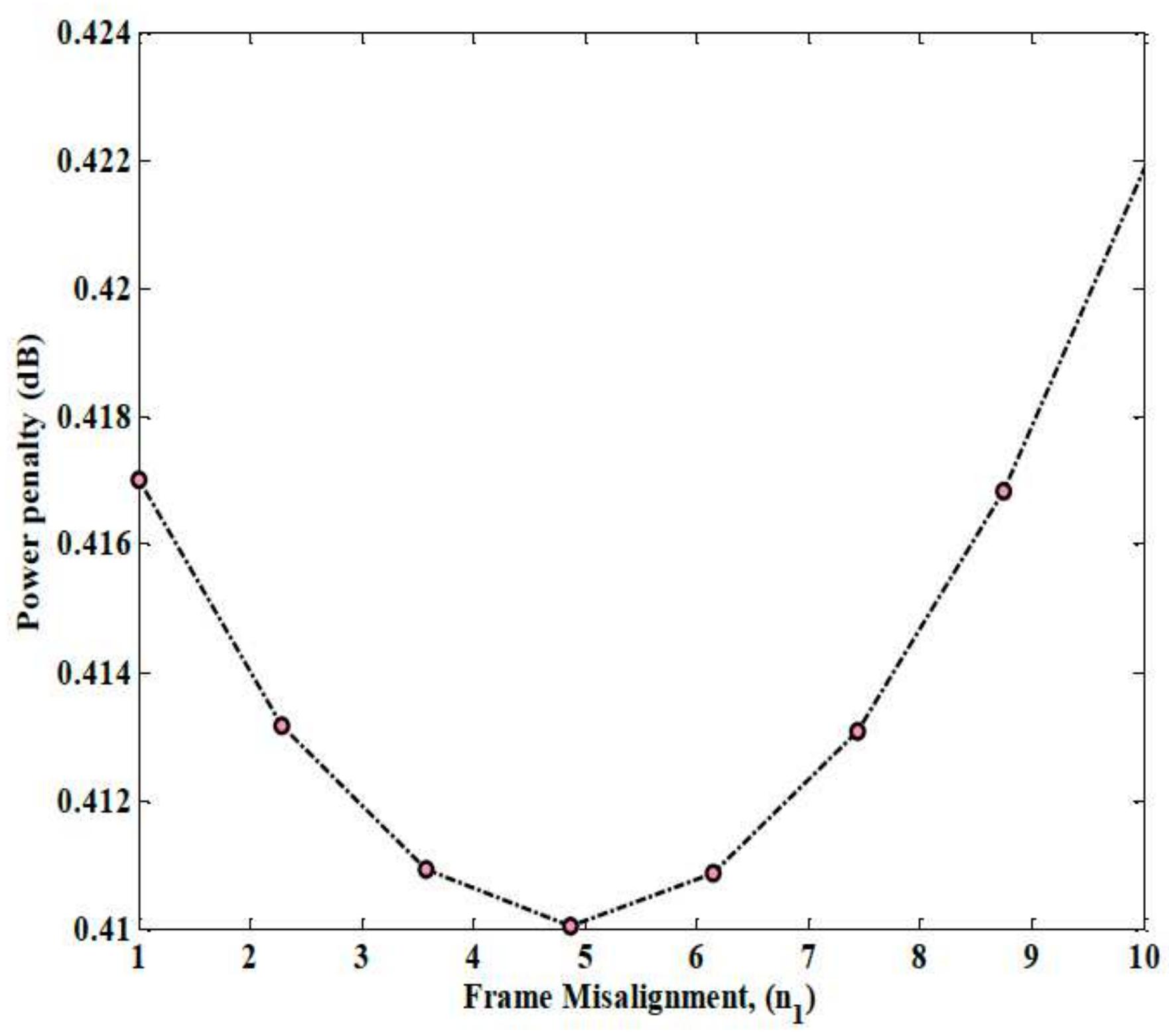

Figure 7

Power penalty as a function of fixed misalignment using MCB (single crosstalk) for $\mathrm{M}=3$ and $\mathrm{C} \_\mathrm{XT}=10$ $\mathrm{dB}$ at $\mathrm{BER}=10^{\wedge}-9$ for Frame misalignment in OSA case. 


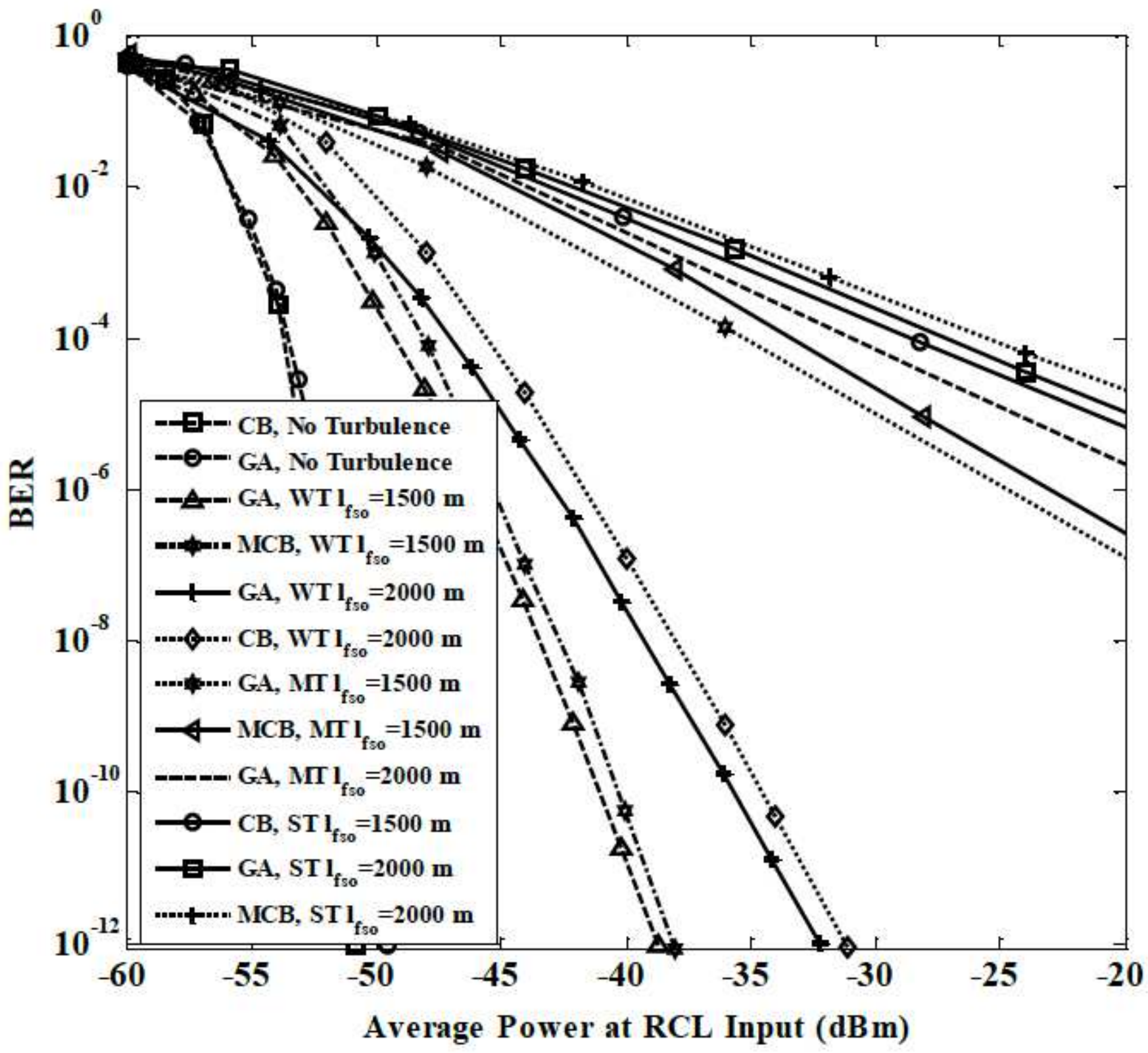

Figure 8

BER vs. average power at receiver collecting lens $(R C L)$ input $(\mathrm{dBm})$ using $M=5$, ffso $=1500 \mathrm{~m}$ and 2000 $\mathrm{m}, \mathrm{G}=30 \mathrm{~dB}, \mathrm{D} \_\mathrm{RX} 1 \mathrm{~mm}$ for no turbulence $(\mathrm{NT})$ and $\mathrm{WT}, \mathrm{MT}$ and $\mathrm{ST}$, all with averaging aperture. 


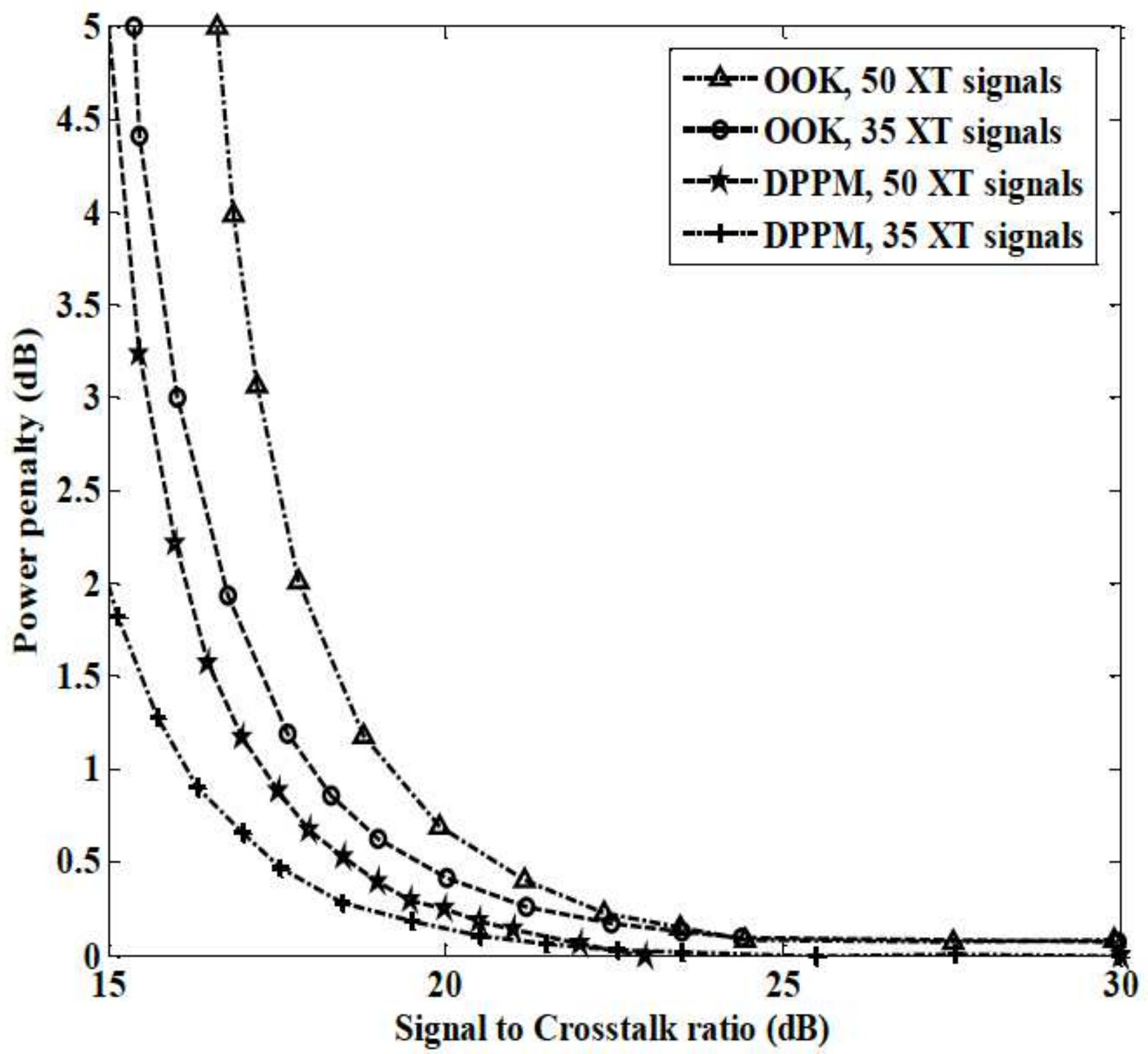

Figure 9

Power penalty against signal-to-crosstalk ratio for OOK and DPPM (multiple crosstalks OSA and simulation) at $\mathrm{BER}=10^{\wedge}-9$ and $\mathrm{OOK}$ comparison with DPPM at $\mathrm{M}=2$. 


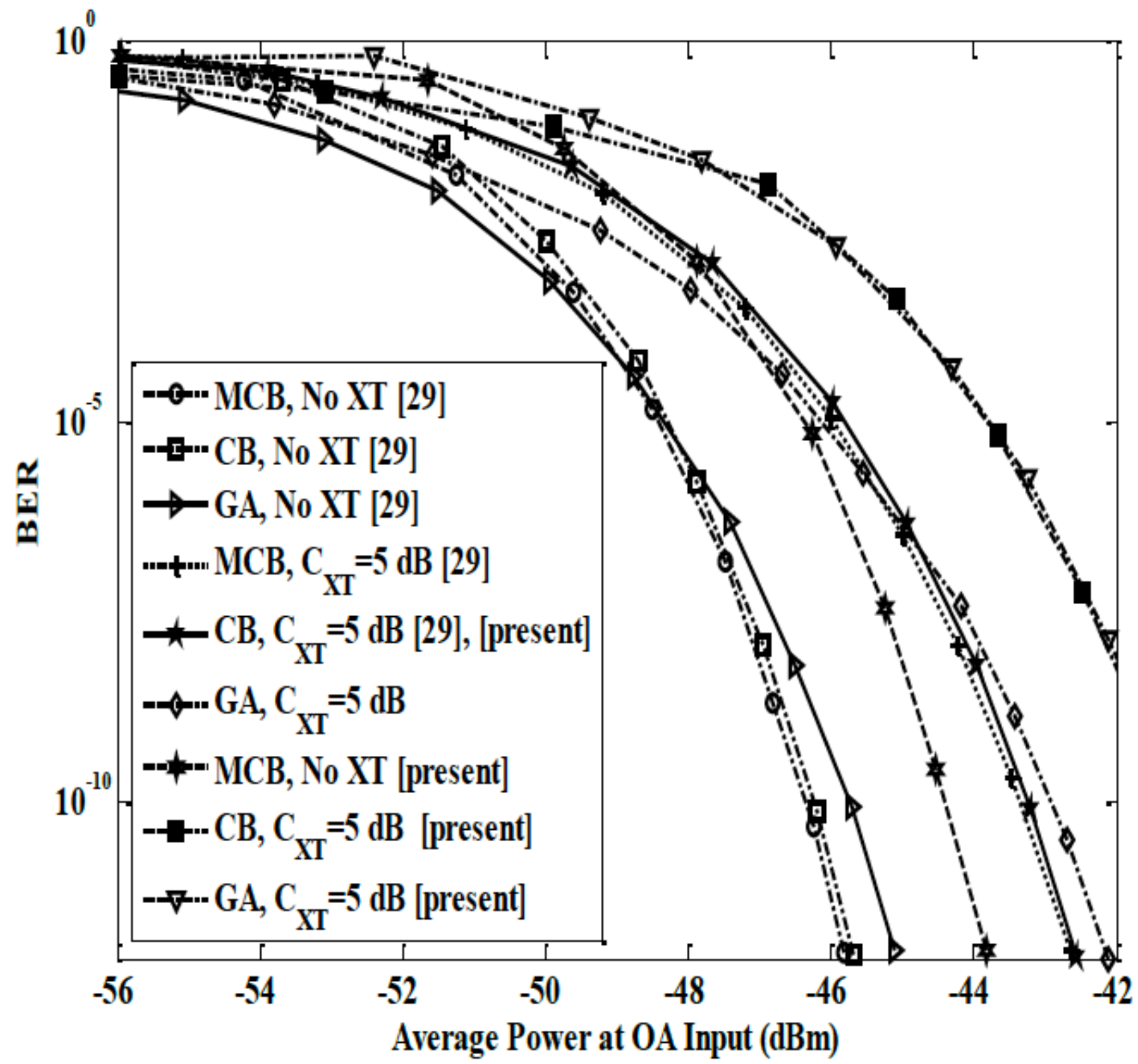

Figure 10

BER against average power at $O A$ input $(\mathrm{dBm})$ using $M=2$, for $F A$ single crosstalk with $C \_X T=5 \mathrm{~dB}, \mathrm{G}=$ $27 \mathrm{~dB}[29]$ and $\mathrm{G}=30 \mathrm{~dB}$ (present]. 

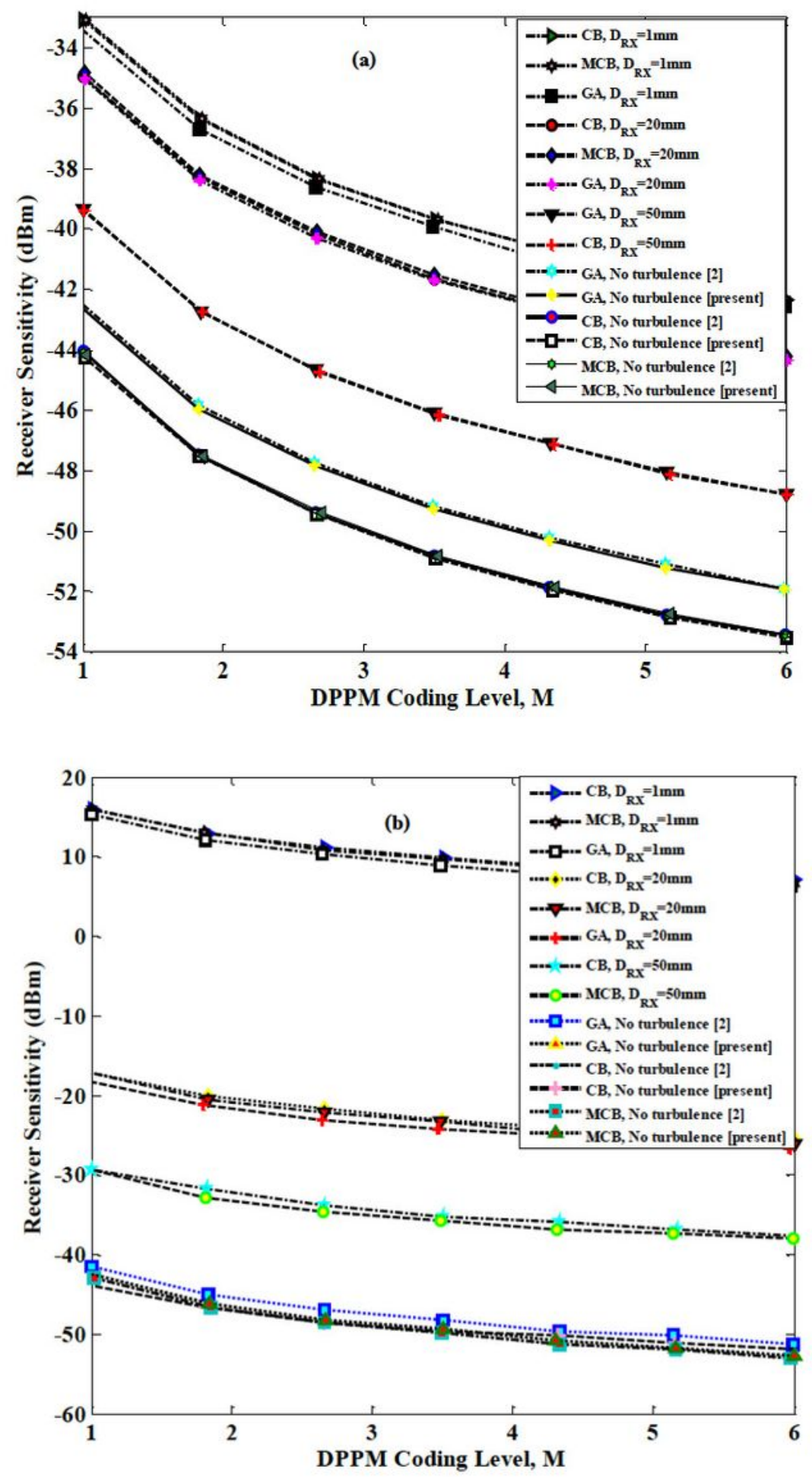

\section{Figure 11}

Receiver sensitivity for each DPPM coding level $(M=1-6)$ is presented for NT with (a) WT and (b) ST (2), (present) 


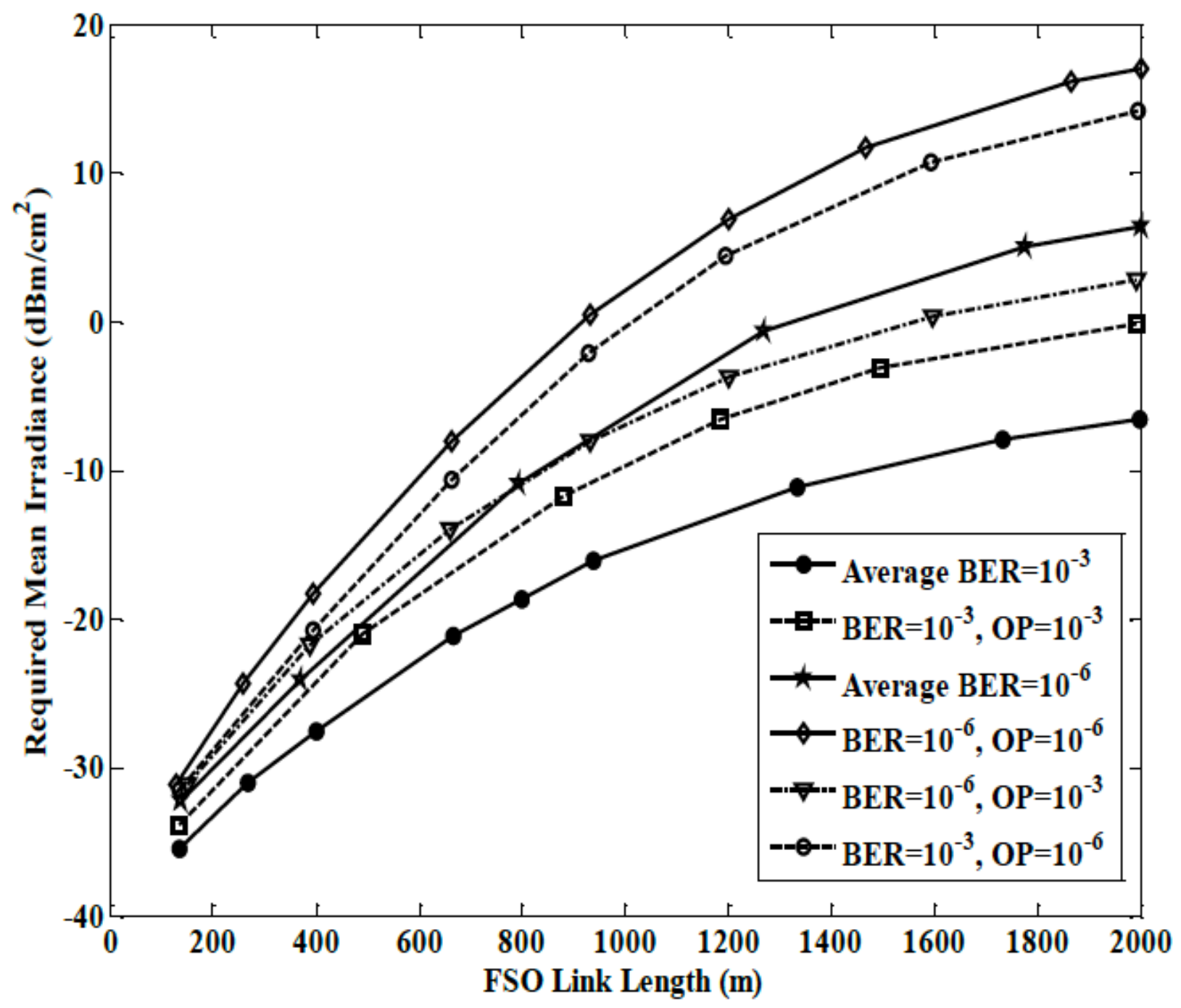

Figure 12

Required mean irradiance as a function of the FSO link length for downstream transmission to achieve instantaneous BER targets with fixed OP values and average BER targets at $L_{-}$demux, $X T=35 \mathrm{~dB}$ and $\mathrm{C} 2 \mathrm{n}=1 \times 10^{\wedge}-13 \mathrm{~m}^{\wedge}-2 / 3$ 


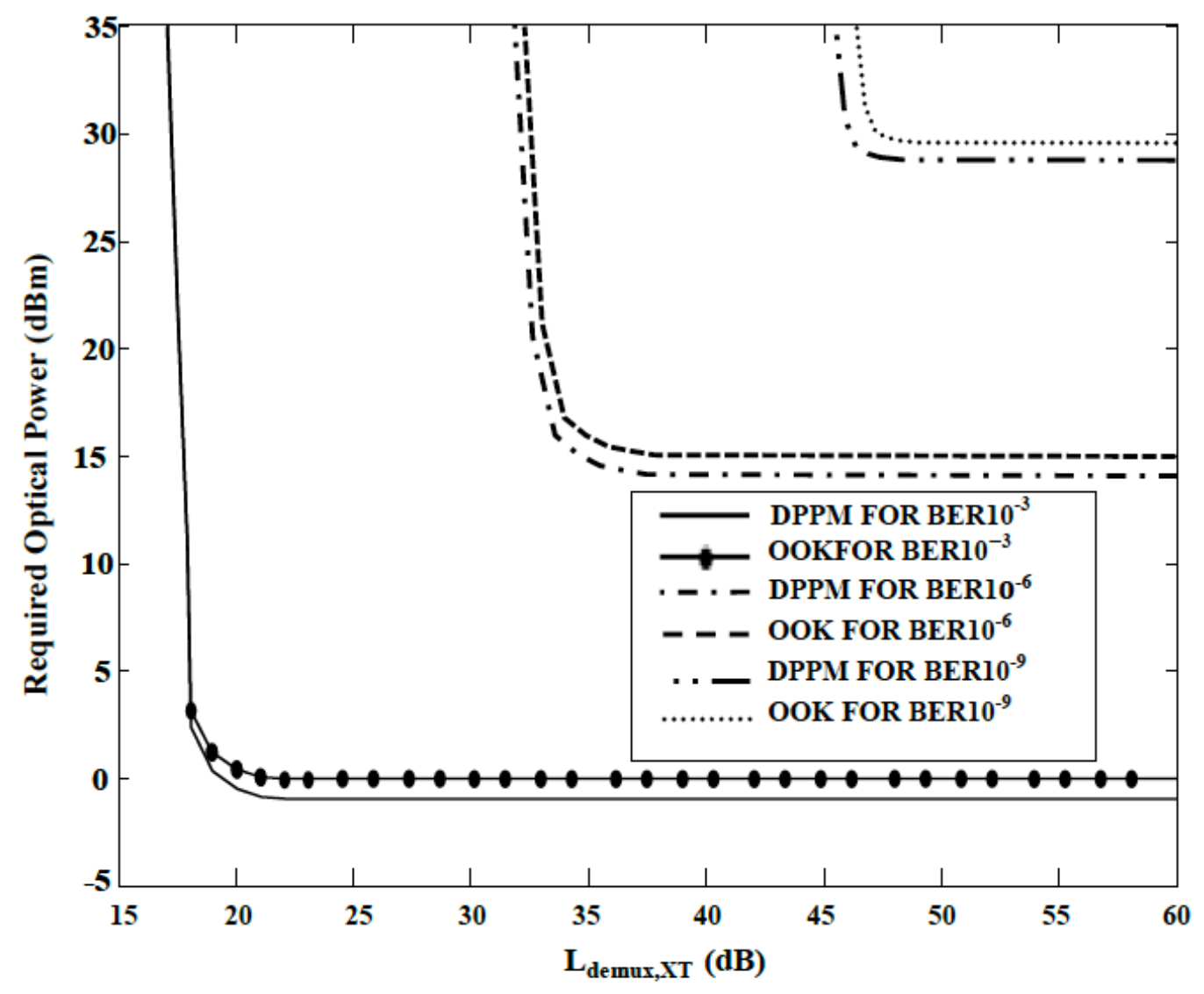

Figure 13

Required optical power $(\mathrm{dBm})$ for the upstream as a function of the refractive index structure constant ( $\mathrm{C} 2 \mathrm{n} \mathrm{m}^{\wedge}-2 / 3$ ) and interferer demux channel rejection $\mathrm{L}_{-}$demux, $X T(\mathrm{~dB}) \int \mathrm{fso}=2000 \mathrm{~m}$. 


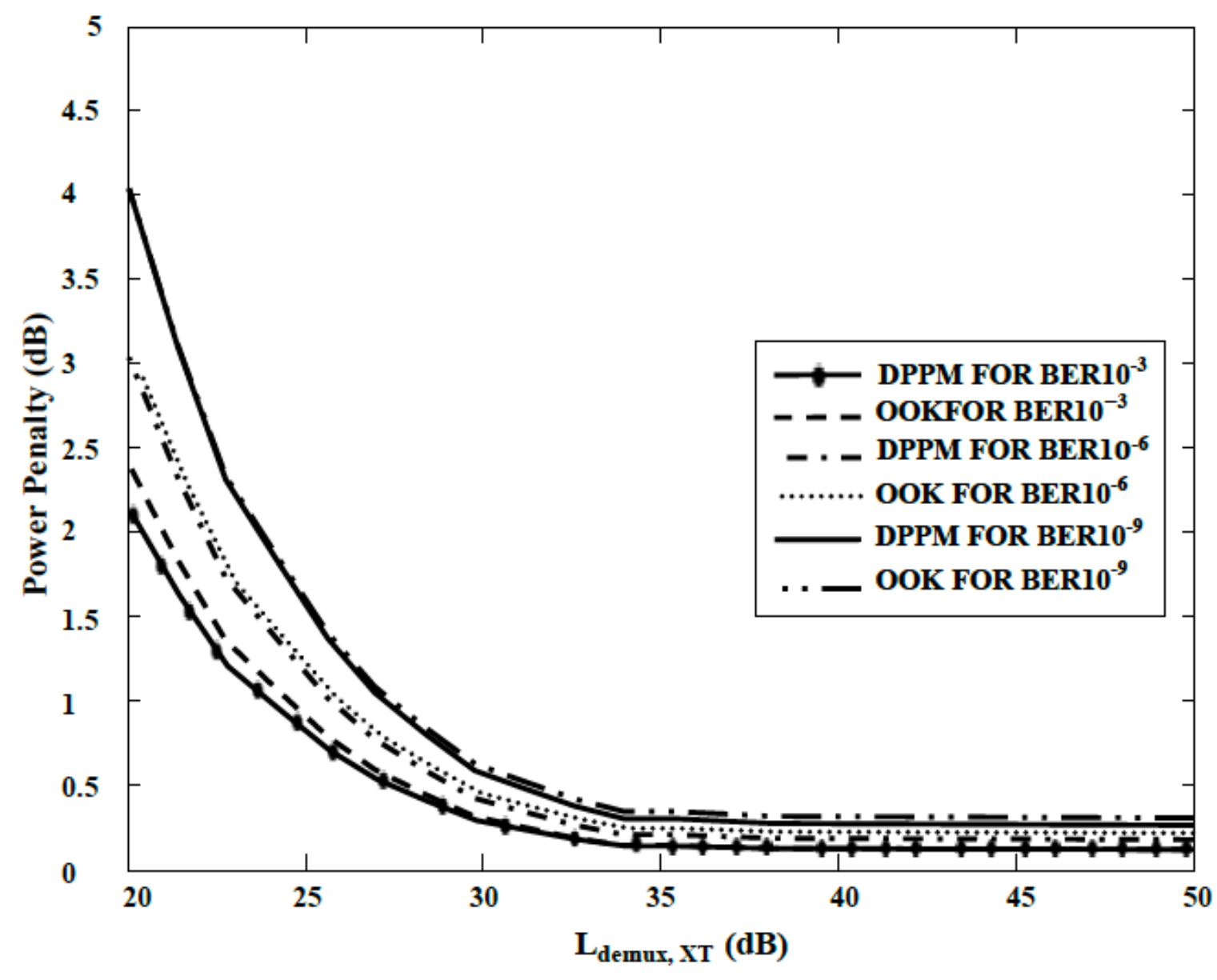

Figure 14

Power penalty $(\mathrm{dB})$ for the upstream as a function of the refractive index structure constant $\left(\mathrm{C} 2 \mathrm{n} \mathrm{m}^{\wedge}-2 / 3\right)$ at $C 2 n=1 e-17 m^{\wedge}-2 / 3$ and interferer demux channel rejection L_demux, XT(dB) at $\int f s o=250 \mathrm{~m}$. 


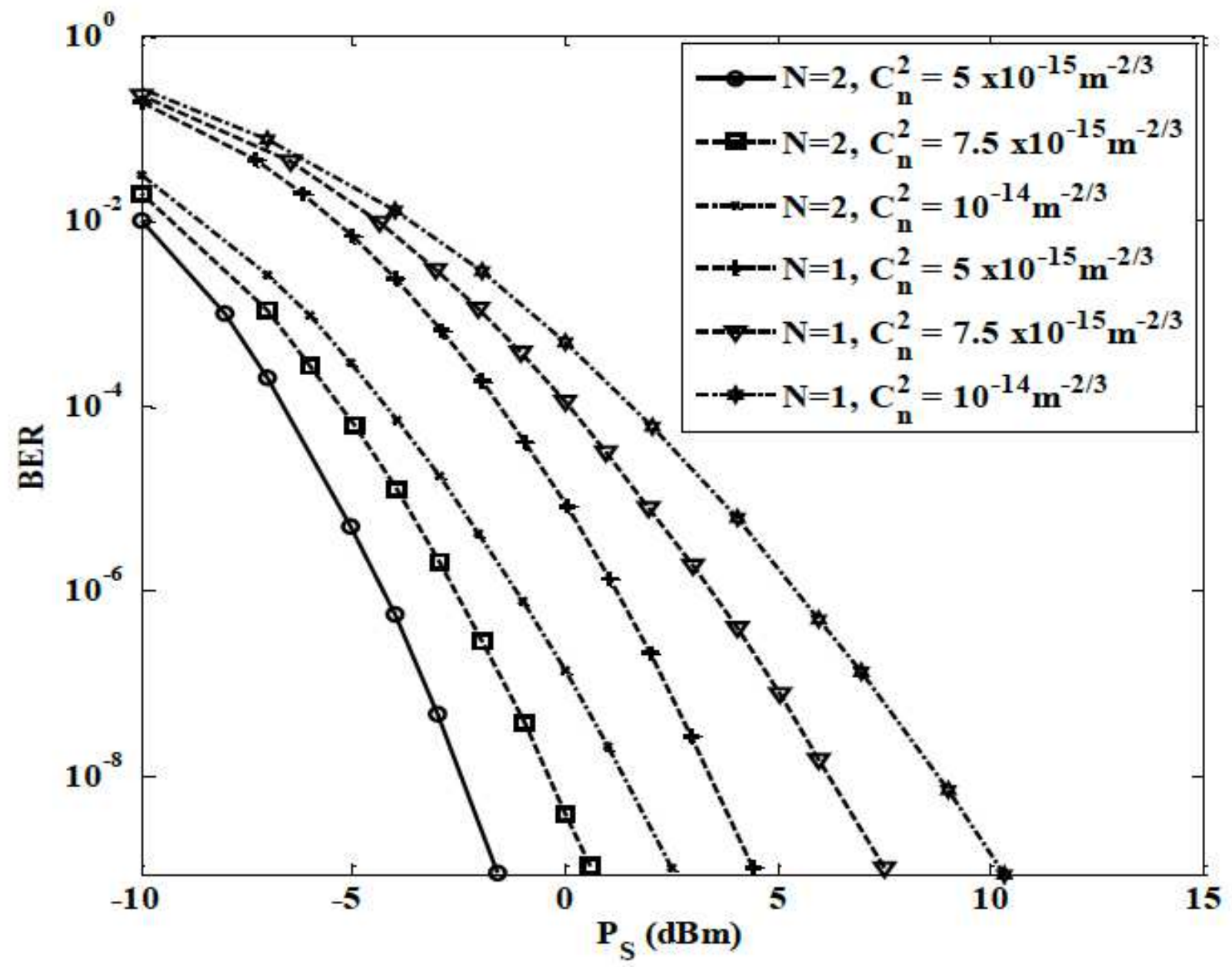

Figure 15

Downstream transmission: $B E R$ versus the average transmitted power per information bit $P$ _s, with 4PPM, R_b = $1 \mathrm{Gbps}$, L_demux, XT = - $30 \mathrm{~dB}$, and $\int \mathrm{fso}=4 \mathrm{~km}$, for different turbulence strengths $\mathrm{C} 2 \mathrm{n} \mathrm{m}^{\wedge}-2 / 3$ 